\title{
TU/e EmonONEN

\section{Spare parts inventory control under a fixed-term contract with a long-down constraint}

\section{Citation for published version (APA):}

Lamghari-Idrissi, D., Basten, R., \& van Houtum, G-J. (2020). Spare parts inventory control under a fixed-term contract with a long-down constraint. International Journal of Production Economics, 219, 123-137. https://doi.org/10.1016/j.jpe.2019.05.023

\section{Document license:}

TAVERNE

DOI:

10.1016/j.jpe.2019.05.023

\section{Document status and date:}

Published: 01/01/2020

\section{Document Version:}

Publisher's PDF, also known as Version of Record (includes final page, issue and volume numbers)

\section{Please check the document version of this publication:}

- A submitted manuscript is the version of the article upon submission and before peer-review. There can be important differences between the submitted version and the official published version of record. People interested in the research are advised to contact the author for the final version of the publication, or visit the $\mathrm{DOI}$ to the publisher's website.

- The final author version and the galley proof are versions of the publication after peer review.

- The final published version features the final layout of the paper including the volume, issue and page numbers.

Link to publication

\section{General rights}

Copyright and moral rights for the publications made accessible in the public portal are retained by the authors and/or other copyright owners and it is a condition of accessing publications that users recognise and abide by the legal requirements associated with these rights.

- Users may download and print one copy of any publication from the public portal for the purpose of private study or research.

- You may not further distribute the material or use it for any profit-making activity or commercial gain

- You may freely distribute the URL identifying the publication in the public portal.

If the publication is distributed under the terms of Article $25 \mathrm{fa}$ of the Dutch Copyright Act, indicated by the "Taverne" license above, please follow below link for the End User Agreement:

www.tue.nl/taverne

Take down policy

If you believe that this document breaches copyright please contact us at:

openaccess@tue.nl

providing details and we will investigate your claim. 


\title{
Spare parts inventory control under a fixed-term contract with a long-down constraint
}

\author{
Douniel Lamghari-Idrissi $^{\mathrm{a}, \mathrm{b}, *}$, Rob Basten ${ }^{\mathrm{a}}$, Geert-Jan van Houtum ${ }^{\mathrm{a}}$ \\ ${ }^{\text {a }}$ Eindhoven University of Technology, Department of Industrial Engineering and Innovation Sciences, Eindhoven, the Netherlands \\ ${ }^{\mathrm{b}}$ ASML Netherlands B.V., Veldhoven, the Netherlands
}

\section{A R T I C L E I N F O}

\section{Keywords:}

Spare parts inventory

Service measure

Markov decision process

Optimal policies

Discrete convexity

\begin{abstract}
A B S T R A C T
We are interested in service contracts for spare parts. We introduce a new performance measure, XLD (extreme long down), that limits the number of deliveries that are later than an agreed threshold during the contract period. We consider a single item, single location stockpoint serving multiple systems where demand is satisfied in an alternative way if the stockpoint is out of stock. Using a finite horizon Markov decision process, we derive the optimal spare parts inventory policy for meeting the contract at minimum costs. We prove that a statedependent and time-dependent base stock policy is optimal. We also prove that the optimal base stock level is non-increasing in the number of allowed extreme long downs in the remaining contract period and that the optimal base stock level decreases at most by one unit per step. We formulate three heuristics for our finite horizon problem. These heuristics are a translation of heuristics commonly used for other service measures than the XLD measure. We assess their performance in comparison to the optimal policy. The results of our numerical study show that Heuristic 3, a myopic heuristic, is the best performing with an average optimality gap of $4.5 \%$ and an optimality gap lower than $5 \%$ in $81 \%$ of the instances. The maximum optimality gap is very high for all three heuristics, showing that important savings can be made by taking into account the actual contract performance and the remaining contract duration in stocking decisions.
\end{abstract}

\section{Introduction}

Capital goods are fixed assets used in the production process of (consumer) goods or services. The capital goods industry plays a key role in the economy with a twelve months revenue of over 1.1 trillion US dollars and an average revenue per employee of almost 400,000 US dollars according to data from CSIMarket (2019). The revenues are supported by two key sources: the sales of new assets and the maintenance of the previously sold assets, the after sales market. The latter is the focus of this paper. Due to the long life cycles of the assets, the installed base of capital goods is continuously increasing. Therefore, the number of systems in the installed base is significantly higher than the number of systems sold within a given year. For example, locomotives see a 22 to 1 ratio (Wise and Baumgartner, 1999). In other words, for every new locomotive sold, twenty-two need to be maintained. Additionally, the maintenance costs over the lifetime of the capital good can be, in some cases, twice as high as its purchase price (Öner et al., 2007). As a consequence, the after sales market has a vast economic impact and potential.
Like most supplier-customer relations, the after sale one is often codified in the form of a contract, more specifically a service contract in which a company, often the original equipment manufacturer (OEM), provides the option to maintain the capital good in exchange of a certain fee. Service contracts generally contain a section on spare parts availability, which is the focus of this paper. For this part of the contract, both inventory management and contract theory are relevant. While the former helps the OEM meet an agreed service level at a minimum cost, the latter tries to secure that the interests of both parties are safeguarded. This combination has led to system-oriented service measures, such as, aggregate mean waiting time and aggregate fill rate becoming the most commonly used service measures in practice (Basten and van Houtum, 2014). The aggregate fill rate is defined as the probability that an arbitrary demand for the total group of stock keeping units (SKU's) is fulfilled immediately. Variations of this performance measure, such as channel fill rate, require a fulfilment within a certain time as opposed to directly from stock. Under a fill rate commitment, there is no commitment from the service provider on how long the customer has to wait in case the component is not delivered

\footnotetext{
${ }^{*}$ Corresponding author. Eindhoven University of Technology, Department of Industrial Engineering and Innovation Sciences, P.O. Box 513, Eindhoven, 5600MB, the Netherlands.

E-mail addresses: d.p.t.lamghari-idrissi@tue.nl (D. Lamghari-Idrissi), r.j.i.basten@tue.nl (R. Basten), g.j.v.houtum@tue.nl (G.-J. van Houtum).
} 
within the agreed time. The aggregate mean waiting time commitment is a step in that direction. It is defined as the expected waiting time until an arbitrary spare part demand is fulfilled. Under an aggregate mean waiting time commitment, the service provider (the OEM or a third party) can compensate a very slow delivery by multiple fast ones. This is possible since there is a commitment on the average waiting time. This balancing of performance erases the link between the service provided and its effects, making it difficult for the customer to assess the performance of the OEM.

Hopp and Spearman (2011) show that, for manufacturing lines, short and frequent interruptions are less harmful than long and infrequent ones. For such situation, the user of the capital good needs to have a guarantee that such long interruptions will happen only a certain number of times for a given period. The outcome of such a guarantee is a reduction of the time to repair variability. This situation occurs at many serial manufacturers, particularly when dealing with the bottleneck resource. Our work is inspired by a situation observed in the practice of ASML, a manufacturer and service provider of lithography systems for the semiconductor industry. Another context where there is pressure to avoid long downs is in information technology and more specifically server farms and data centres. Further applications can be seen in the airline industry. This constitutes a gap in the currently available service measures.

We introduce the XLD service measure (XLD stands for extreme long down), which limits the number of outliers in the time to repair. We believe that our XLD service measure closes the identified gap as, in some contexts, the value of a spare parts service contract resides in decreasing variability of the time to repair. This allows to make a direct link between the OEM providing the spare parts and the outcome for the user. This service measure sets a target that is independent of the realized number of demands during the contract period. In other words, the target is not expressed in the form of a fraction, an average, a probability or an expectation. This change is very relevant for the customer who needs to plan the utilization of her assets. Under the XLD service measure, she knows that for a given period, there will not be more than a set number of hurtful long outages. For example, in practice, the constraint could be formulated in a contract in the following way: a down longer than $G$ consecutive hours can only occur K times for a group of systems over the course of the contract. The downtime can be split into multiple steps. First an engineer performs a diagnostic as a result of which (s)he requests and receives the required spare part. Upon receipt, (s)he can perform the swap and proceed with a recovery sequence (restart of the equipment). We are interested in studying how to stock spare parts to meet a certain downtime duration limit within the contract execution period and at minimal costs. Assuming that the diagnostic, swap and recovery times are deterministic, our example could be reformulated as, with $H<G$ : a spare part waiting time longer than $H$ can only occur $K$ times for a group of systems over the course of the contract.

We consider a single item, single location stock point serving multiple systems. In this way, we model a situation where there is a contract for one component, which is swapped after failure by a functioning one. After the swap, the whole defective module gets repaired in a repair shop before being returned to stock. In the case of the airline industry, it could be a contract covering only the landing gear of a fleet of planes, for example. Demand fulfilled directly from the closest stockpoint would be fulfilled on time, while demand fulfilled via an alternative way, i.e., an emergency shipment would be late and would create a long down, we model a single location. The contract holds for a group of systems. This contract has one fixed duration, one service measure and one target. The contract duration is divided in review periods. On a periodic basis, planners review the contract performance and on-hand inventory and decide how much to order. The replenishment lead time is very short in comparison to the review period. Therefore, we set the replenishment lead time at zero. In the case where the demand in a period would be higher than the stock available, the unfulfilled demand is satisfied via an emergency shipment.

Our main contributions are as follows. First, we introduce a new service measure, XLD (extreme long down), which limits the number of spare parts delivered later than an agreed threshold. Second, using a finite horizon Markov decision process, we prove that the optimal policy is a state-dependent and time-dependent base stock policy. Third, we also formulate three heuristics for our problem. These heuristics are a translation of heuristics commonly used for other service measures than the XLD measure. We compare our optimal policy to these heuristics to see how well they perform. We find that Heuristic 3, a myopic heuristic, is the best performing with an average optimality gap of $4.5 \%$ and 66 out of the 81 instances having an optimality gap of at most $5 \%$ but a maximum optimality gap of $49 \%$.

The paper is organized as follow. In Section 2, we cover the literature on service measures and finite horizon models to highlight our contribution. In Section 3, we introduce the problem formally and formulate it as a finite horizon Markov decision process. Section 4 shows the structural results and Section 5 gives the heuristics that we use in Section 6 to assess the performance of the optimal policy and to derive managerial insights. We conclude in Section 7.

\section{Literature review}

Sherbrooke (1968) is the foundational work of the field of spare parts inventory management. Driven by the low demand environment of the military, he developed the METRIC method to optimize repairable spare parts stock levels. Since then, the optimization of spares parts inventory has been widely studied, up to including the use of additive manufacturing as alternative supply (Knofius et al., 2019) or evaluating the impact of workforce training policies on spare parts inventory (Sleptchenko et al., 2019). We refer the interested reader to Basten and van Houtum (2014) and Hu et al. (2018) for comprehensive literature reviews on system-oriented inventory models. To highlight our contribution, we focus our literature review on service measures in Section 2.1, on finite horizon in Section 2.2 and on state-dependent base stock policies in Section 2.3.

\subsection{Service measures}

Sherbrooke (1968) introduces the fill rate as a service measure representing the fraction of demand fulfilled directly from stock. Building on the fill rate and looking at the customer's experience, Berg and Posner (1985, page 287) propose customer delay as being "the amount of time the customer is expected to wait in the queue before leaving the system", in other words, the sojourn time. In the after sale context, this represents the expected waiting time until the demand for a spare part is fulfilled. Song (1998) proposes to focus at the order level, by defining the order fill rate, measuring the probability of filling an entire customer order immediately from the shelf or, more generally, within a prespecified time window. Caggiano et al. (2007, page 304) define the channel fill rate as "the probability that an arriving demand for a part will be satisfied within a specified amount of time". Since then, the concept of channel fill rate has been further studied and variants of it proposed. For example, Larsen and Thorstenson (2014, page 17) introduce the customer order fill rate and define it as "the average fraction of each customer order that is immediately fulfilled from inventory". While the order fill rate measures the percentage of orders which are served in full, the customer order fill rate allows for partial fulfilment of an order and therefore, it measures an average fraction. Dreyfuss and Giat (2017, page 584) take into account customer patience and introduce the truncated waiting time and the window fill rate. The truncated waiting time represents "the expected time waited beyond $t$ units of time" while the window fill rate is "fill rate during a time window of $t$ ". This service measure is similar to channel fill rate but uses stochastic lead times with a general distribution as opposed to deterministic lead times for each channel. 
The service measure we propose is very different from the existing ones as it is a more direct performance measure. It is not based on average, expectation or fraction; it is a fixed number. The customer gets an actual commitment that there will not be more than an agreed number of extreme long downs. It, therefore, provides more certainty to the customer and helps her plan her operations.

\subsection{Finite horizon}

By considering the contract duration, we place ourself in a finite horizon setting, which has received less attention than the infinite horizon one. One of the key differences is that in a finite horizon, the achieved performance, be it fill rate or another measure, is a random variable. Chen et al. (2003) show that, when demand is independent and identically distributed, the multi-period expected fill rate is below the one period expected fill rate and above the expected infinite horizon fill rate. Banerjee and Paul (2005) extend their work by proving that the expected fill rate over a finite horizon is a monotonically decreasing function of the number of periods in the horizon. Thomas (2005) studies how the fill rate achieved during the total contract period is affected by the length of the review horizon, the demand distribution and the penalties incurred for not meeting the agreed level. He shows that, when high penalty costs are to be incurred if a target fill rate is not met during a review period, the customer is actually asking a long-run fill rate that is much higher than the one targeted within the review period.

Kim et al. (2010) show that performance-based contracting can yield suboptimal results in the case of highly reliable equipment. The high reliability in combination with the finite horizon of the contract means that there are only very few observations. The occurrences being limited, the performance realized by the OEM might not be representative of its readiness. Developing further the effect of a finite horizon on contract realization, Al Hanbali and van der Heijden (2013) derive the first two moments of the probability distribution of meeting the target of a service contract at the end of the horizon. They study the probability to actually meet the target. They show that when planning for the steady-state situation, there is a high risk of not meeting the availability target within the contract execution period. Ge et al. (2018) extend their work by explicitly taking into account the uncertainty in the component failure rates, the stochastic nature of the number of failures during a service contract period, and the stochastic repair times. To allow for fast approximate evaluation, they develop the fulluncertainty method and show the benefits of taking the variation occurring during the contract period into account. Another setting where the length of the horizon needs to be accounted for is when studying warranty mechanisms. For example, Luo and Wu (2018) focus on a nonrenewing free replacement warranty policy under which the manufacturer provides its customers with repair or replacement at no cost within the warranty period. They provide a collective warranty optimization policy by assuming a linear relationship between the length of the warranty coverage, the warranty price and quantity of product sold.

Based on previous work, it is clear that, in practice, the contract duration cannot be ignored and should be counted for. If not, the related uncertainty will manifest itself in the profitability of the service contract either via higher than necessary holding costs or via expensive emergency costs and potentially penalties. Previous work shows that meeting the contract performance in a finite horizon is a random variable. To the best of our knowledge, it is the first time that a dynamic optimal policy is derived in order to meet a service level agreement by the end of the contract duration.

\subsection{State-dependent base stock policies}

When using Markov decision processes, it is often the case that the optimal policy is a state-dependent base stock policy. In discrete time, the structure of these policies is notoriously difficult to prove and has led to intensive research in mathematics of operations research. Murota
(2003) introduces the concepts of L-convex and M-convex functions. The key difference between them is that the former is defined on lattices and the latter on matroids. These functions are more tractable than previously used ones and bring additional combinatorial properties. Zipkin (2008) uses $\mathrm{L}^{\natural}$-convexity, a type of L-convex functions, for the structural analysis of a standard single-item lost sales inventory system. Using this property, he is able to prove, for the first time in the lost sales context, that more variable demand leads to higher costs. More recently, Topan et al. (2018) study the effect of using imperfect advanced demand information in stocking decisions. Using $\mathrm{L}^{\natural}$-convexity, they prove that the optimal policy for their model is also a state-dependent base stock policy. Even though $\mathrm{L}^{\natural}$-convexity is a powerful tool, it is an indirect way of proving. The original variables first need to be converted into complementary variables. $\mathrm{L}^{\natural}$-convexity is then used to show the structural properties with respect to the new variables. To complete the analysis, the properties need to be transformed back to those with respect to the original variables.

There exists a direct approach which uses multimodularity. Hajek (1985) introduced multimodular functions, which are the discrete equivalent of convex functions. It is interesting to note that $\mathrm{L}^{\natural}$-convexity and multimodularity are related through a unimodular coordinate transformation (Murota, 2005). When focusing on two-dimensional problems, the diagonal dominance needed for $\mathrm{L}^{\natural}$-convexity is equivalent to the superconvexity needed for multimodularity (Song et al., 2017). Superconvexity is a very important property regarding the structure of a state-dependent policy though seldomly used. In a recent paper, van Wijk et al. (2019) prove the existence of thresholds in their state-dependent policy using superconvexity and supermodularity. For two-dimensional problems, the combination of these two properties is equivalent to multimodularity (Koole, 2007).

To the best of our knowledge, our work is the first to prove that a state-dependent base stock policy is optimal for a lost sales model with both emergency and penalty costs. We do this in a finite horizon setting, using the direct approach (i.e., using multimodularity).

\section{Model}

In Section 3.1, we introduce the problem, the assumptions and the notation. The formulation as a Markov decision process is given in Section 3.2.

\subsection{Description and assumptions}

We consider a single item stockpoint that fulfils demand from $N$ systems in the field. A service contract covers a critical module or component of the system. Upon a failure of the critical component, the system comes to a halt until the defective component is swapped for a functioning one such as an aeroplane engine or the motor of a production line. All systems are of the same type and they all belong to the same customer. The contract is closed with this customer and applies to the demands of all systems together. The service contract allows for a fixed number of demands $K^{\text {obj }} \in \mathbb{Z}^{+}$to be fulfilled later than a predefined amount of time (e.g., $12 \mathrm{~h}$ ) over a predefined period consisting of $T$ periods of equal length (e.g., 50 weeks). Should the number of late deliveries exceed $K^{\text {obj }}$, the OEM will pay a penalty with $\operatorname{cost} c^{\mathrm{p}}$ for each additional late delivery. In our model, we keep track of the number of periods remaining until the end of the contract. The $\operatorname{cost} c^{\mathrm{p}}$ is typically high as it covers not only the monetary value but also the frustration of the customer, which translates into future lost opportunities. Hence, it makes a real incentive to meet the constraint of at most $K^{\text {obj }}$ late deliveries.

To fulfil the demand, the OEM stocks spare parts in a single stockpoint close to the customer. The stockpoint is replenished by a regional or a central stockpoint of the OEM. The lead time is very short compared to the period duration. As a consequence, we consider the replenishment lead time to be equal to zero. The stockpoint is close 
enough to the customer to neglect the shipment time from the stockpoint to the systems of the customer. When the demand is fulfilled by the local stockpoint, the system is operational again within the time limit. When the demand cannot be fulfilled by the local stockpoint, it is a lost sale for the local stockpoint and it gets fulfilled via an emergency shipment from another location against an additional cost $c^{\mathrm{e}}$. We assume that every emergency shipment is a late delivery and, therefore, counts as a late delivery. The emergency shipment cost is typically low in comparison to the penalty cost.

At the beginning of each period, the level to which the inventory is increased, $S$, is reassessed based on two parameters: the current contract performance, $K$, i.e. the number of late deliveries that is still allowed for the remaining contract duration, and the current on-hand stock, $I$. In a real life setting, a planner would look into these two elements every Monday morning, for example, and decide how much stock is needed for the week. Let $c^{\mathrm{h}}$ denote the holding costs which are composed of warehousing, insurance and the cost of capital. The holding costs are paid on the remaining on-hand inventory at the end of each period.

We assume that each period is small compared to the total contract duration. Therefore, each system can fail only once per period with probability $p$ and will be repaired within the same period. This means that, during a period, the demand cannot exceed the number of systems in the installed base. This makes sense in practice especially for high tech systems that see low numbers of failures. Because the replenishment lead time equals zero, it is never optimal to increase the stock level to a higher level $S$ than $N$ at the beginning of a period. Additionally, $S$ can only be higher or equal to $I$. Let $X$ be the number of system failures in an arbitrary period, i.e., the demand received at the stockpoint during one period. $X$ is a binomially distributed random variable with parameters $N$ and $p$, i.e.:

$\mathbf{P}\{X=d\}=\frac{N !}{(N-d) ! d !} p^{d}(1-p)^{(N-d)}, \quad 0 \leq d \leq N$.

The sequence of events in each period is as follows:

- The state, consisting of $K$ and $I$, is observed.

- Parts are ordered and received.

- Demand during one period is observed and fulfilled:

- The total demand is fulfilled from stock if $X \leq I$;

- In case $X>I$, then $I$ demands are fulfilled from stock, while the other demands are fulfilled via an emergency shipment (lost sale to the stockpoint).

- All costs are incurred.

Our objective is to derive the optimal policy to meet the service level agreement target within the contract duration and at minimum costs.

\subsection{MDP formulation}

Our optimization problem can be formulated as a Markov Decision Process. Let $\mathscr{S}=\{0,1, \ldots, N\}$ denote the set of possible stock levels and $\mathscr{K}=\left\{0,1, \ldots, K^{\text {obj }}\right\}$ the set of possible XLD levels. We define the lattice $\mathscr{L}=\mathscr{S} \times \mathscr{K}$. Let $V_{t}(K, I)$ be the optimal remaining cost until the end of the contract period when the system is in state $(K, I)$ at the start of period $t \in\{1,2, \ldots, T\}$. After ordering up to $S \in \mathscr{S}$, the direct expected costs in the period are:

$$
\begin{aligned}
& C(K, S)=\sum_{d=0} N_{\mathbb{P}\{X=d\} c(K, S, d), \text { where: }} \\
& c(K, S, d)=c^{\mathrm{h}}(S-d)^{+}+c^{\mathrm{e}}(d-S)^{+}+c^{\mathrm{p}}(d-S-K)^{+} .
\end{aligned}
$$

We define:

$$
\begin{gathered}
\tilde{V}_{t+1}(K, S)=C(K, S)+\sum_{d=0}^{N} \mathrm{P}\{X=d\} V_{t}\left(\left(K-(d-S)\left(\left(K-(d-S)^{+}\right)\right)^{+},\right.\right. \\
\left.(S-d),(S-d)^{+}\right), S \in \mathscr{S}, K \in \mathscr{K}, t \in\{0, \ldots, T-1\} .
\end{gathered}
$$

The Bellman equation for our optimization problem is given by:

$V_{t+1}(K, I)=\min _{S \in\{I, \ldots, N\}} \tilde{V}_{t+1}(K, S), I \in \mathscr{S}, K \in \mathscr{K}, t \in\{0, \ldots, T-1\}$,

$V_{0}(K, I)=0, I \in \mathscr{S}, K \in \mathscr{K}$.

Since this is a finite horizon MDP, we compute the optimal policy using backward induction. Over the complete contract duration, the total expected costs of the optimal policy are given by $V_{T}\left(K^{\text {obj }}, 0\right)$.

\section{Analysis}

In this section, we study the structural properties of our model. All proofs are given in Appendix A.

Definition 1. Let $\mathscr{Z}$ be a two-dimensional lattice. We define $i \in \mathbb{Z}^{+}$and $j \in \mathbb{Z}^{+}$. Let $e_{i}$ and $e_{j}$ denote the unit vector of appropriate length, consisting of all zeros except for a 1 at position $i$ and $j$ respectively. Adopting the terminology of Koole (2007), consider the following properties of a function $f$ on $\mathscr{Z}$, defined for all $x$ such that the states appearing in the right-hand and left-hand side of the inequalities exist in our state space:

- Non - decreasing $(i): f\left(x+e_{i}\right) \geq f(x)$;

- Non - increasing $(i): f\left(x+e_{i}\right) \leq f(x)$;

- Convex $(i): f(x)+f\left(x+2 e_{i}\right) \geq 2 f\left(x+e_{i}\right)$;

- Supermodular: $f(x)+f\left(x+e_{i}+e_{j}\right) \geq f\left(x+e_{i}\right)+f\left(x+e_{j}\right)$;

- Superconvex $(i, j): f\left(x+2 e_{i}\right)+f\left(x+e_{j}\right) \geq f\left(x+e_{i}\right)+f\left(x+e_{i}+e_{j}\right)$

- SuperConvex $=\cap_{1 \leq i, j \leq \mathbb{Z}^{+}: i \neq j} \operatorname{Superconvex}(\mathrm{i}, \mathrm{j})$

- Multimodular $=$ Supermodular $\cap$ SuperConvex.

Lemma 1. The function $c(K, S, d)$ has the following properties for each $d \in\{0, \ldots, N\}$ :

(i) For each $S \in \mathscr{S}, c(K, S, d)$ is non-increasing in $K \in \mathscr{K}$.

(ii) For each $S \in \mathscr{S}, c(K, S, d)-c(K+1, S, d) \leq c^{p}$ for $K \in \mathscr{K}$.

(iii) For each $S \in \mathscr{S}, c(K, S, d)$ is convex in $K \in \mathscr{K}$.

(iv) For each $K \in \mathscr{K}, c(K, S, d)$ is convex in $S \in \mathscr{S}$.

(v) $c(K, S, d)$ is supermodular on $\mathscr{L}$.

(vi) $c(K, S, d)$ is superconvex $(S, K)$ on $\mathscr{L}$.

(vii) $c(K, S, d)$ is superconvex $(K, S)$ on $\mathscr{L}$.

Parts (i) and (iv) make sense intuitively. Part (i) states that the higher the number of allowed late deliveries, the lower the direct costs. The direct cost function being convex in S, see part (iv), means that there exists an optimal base stock level which minimises the direct costs. Part (v) states that the direct costs increase "faster" as the contract performance decreases and the stock increases. This is due to the probability of paying penalty costs being much higher for a lower K. Additionally, as S increases, the probability of overstocking is higher translating into higher than necessary holding costs. The properties for $c(K, S, d)$ lead directly to the same properties for the direct expected costs $C(K, S)$.

Lemma 2. The direct expected costs function $C(K, S)$ has the following properties:

(i) For each $S \in \mathscr{S}, C(K, S)$ is non-increasing in $K \in \mathscr{K}$.

(ii) For each $S \in \mathscr{S}, C(K, S)-C(K+1, S) \leq c^{p}$ for $K \in \mathscr{K}$.

(iii) For each $S \in \mathscr{S}, C(K, S)$ is convex in $K \in \mathscr{K}$.

(iv) For each $K \in \mathscr{K}, C(K, S)$ is convex in $S \in \mathscr{S}$.

(v) $C(K, S)$ is supermodular on $\mathscr{L}$. 
(vi) $C(K, S)$ is superconvex $(S, K)$ on $\mathscr{L}$.

(vii) $C(K, S)$ is superconvex $(K, S)$ on $\mathscr{L}$.

Next we study the properties of the total expected costs function. We prove that the optimal policy is state-dependent and time-dependent. Furthermore, we prove that the optimal base stock level is non-increasing in $K \in \mathscr{K}$.

Theorem 1. A. For $t \in\{1, \ldots, T\}, \tilde{V}_{t}(K, S)$ has the following properties:

(i) For each $S \in \mathscr{S}, \tilde{V}_{t}(K, S)$ is non-increasing in $K \in \mathscr{K}$.

(ii) For each $S \in \mathscr{S}, \tilde{V}_{t}(K, S)-\tilde{V}_{t}(K+1, S) \leq c^{p}$ for $K \in \mathscr{K}$.

(iii) $\tilde{V}_{t}(K, S)$ is superconvex $(S, K)$ on $\mathscr{L}$.

(iv) $\tilde{V}_{t}(K, S)$ is superconvex $(K, S)$ on $\mathscr{L}$.

(v) $\tilde{V}_{t}(K, S)$ is supermodular on $\mathscr{L}$.

(vi) For each $K \in \mathscr{K}, \tilde{V}_{t}(K, S)$ is convex in $S \in \mathscr{S}$.

(vii) For each $S \in \mathscr{S}, \tilde{V}_{t}(K, S)$ is convex in $K \in \mathscr{K}$.

B. For $t \in\{0, \ldots, T\}, V_{t}(K, I)$ has the following properties:

(i) For each $K \in \mathscr{K}, V_{t}(K, I)$ is convex in $I \in \mathscr{S}$.

(ii) A state-dependent base stock policy is optimal in each time period. Let $S_{t}^{*}(K)$ denote the optimal base stock level at time $t ; S_{t}^{*}(K)$ is the lowest $S$ for which $\tilde{V}_{t}(K, S) \leq \tilde{V}_{t}(K, S+1)$.

(iii) For each $t$, the optimal base stock level $S_{t}^{*}(K)$ is non-increasing in $K$ and $S_{t}^{*}(K+1) \leq S_{t}^{*}(K) \leq S_{t}^{*}(K+1)+1$.

(iv) For each $K \in \mathscr{K}, V_{t}(K, I)$ is non-decreasing in $I \in \mathscr{S}$.

(v) For each $I \in \mathscr{S}, V_{t}(K, I)$ is non-increasing in $K \in \mathscr{K}$.

(vi) For each $I \in \mathscr{S}, V_{t}(K, I)-V_{t}(K+1, I) \leq c^{p}$ for $K \in \mathscr{K}$.

(vii) $V_{t}(K, I)$ is superconvex $(I, K)$ on $\mathscr{L}$.

(viii) $V_{t}(K, I)$ is superconvex $(K, I)$ on $\mathscr{L}$.

(xi) $V_{t}(K, I)$ is supermodular on $\mathscr{L}$.

(x) For each $I \in \mathscr{S}, V_{t}(K, I)$ is convex in $K \in \mathscr{K}$.

The superconvexity property plays a key role in proving Theorem 1 . The property is used, in combination with supermodularity, to prove convexity in each variable. It is important to note that, while superconvexity and supermodularity imply convexity, supermodularity and convexity do not imply superconvexity. Furthermore, supermodularity of $\tilde{V}_{t}(K, S)$ gives us that the optimal base stock levels are non-increasing in $\mathrm{K}, \tilde{V}_{t}(K, S)$ being superconvex $(S, K)$ gives us $S_{t}^{*}(K) \leq S_{t}^{*}(K+1)+1$. In addition to the managerial insight it brings, this result is key to the Proof as it gives a more refined relationship between the different optimal, i.e., state-dependent, base stock levels. This is needed in order to precisely enumerate all the different cases to be assessed for proving the subsequent properties.

Directly from Definition 1, we have the following result.

Corollary 1. $c(K, S, d), C(K, S), \tilde{V}_{t}(K, S)$ and $V_{t}(K, I)$ are multimodular.

Fig. 1 depicts the behaviour of the optimal base stock level $S_{t}^{*}(K)$ for the specified values of $N, K^{\mathrm{obj}}, p, c^{\mathrm{h}}, c^{\mathrm{e}}, c^{\mathrm{p}}$ and with $T=50$. As per the aforementioned structural properties, the state-dependent and timedependent base stock policy is clearly illustrated. It can also be seen that the optimal base stock level is non-increasing for a given value of $K$, for example, $S_{t}^{*}(3) \leq S_{t}^{*}(2) \leq S_{t}^{*}(3)+1, \forall t \in\{0,1, \ldots, T\}$.

\section{Heuristics}

Because the XLD constraint is new, there exists no heuristic in the literature that can be applied directly. In this section, we develop new heuristics, mirroring the logic of common heuristics for other service measures and analyse how they perform compared to the optimal policy. In Section 5.1, the heuristic developed is an XLD variant of a steady-state base stock policy while the heuristics developed in Section 5.2 and 5.3 are XLD variants of a finite horizon base stock policy and a myopic policy respectively.

To evaluate the costs under the use of a state-independent, time- independent base stock policy, we introduce $\bar{V}_{t}^{S}(K)$ as the expected costs obtained in $t$ periods when following a base stock policy $S \in \mathscr{S}$ while being allowed to have $K$ late deliveries. It holds that:

$$
\begin{aligned}
\bar{V}_{0}^{S}(K)= & 0, \text { for } K \in \mathscr{K} \text { and, for } t \in\{1, \ldots, T\}, \\
\bar{V}_{t}^{S}(K)= & C(K, S)+\sum_{d=0}{ }^{N} \mathbb{P}\{X=d\} \bar{V}_{t-1}^{S}((K \\
& \left.-(d-S)\left(\left(K-(d-S)^{+}\right)\right)^{+}\right), \text {for } K \in \mathscr{K}, S \in \mathscr{S} .
\end{aligned}
$$

The total expected costs under base stock policy $S$ are equal to $\bar{V}_{T}^{S}\left(K^{\text {obj }}\right)$.

\subsection{Heuristic 1}

We define a policy that uses the base stock level that minimizes the expected costs over an infinite horizon, without considering the contract performance or duration. The base stock level is set to meet the targeted service level in steady-state. This policy is, therefore, stateindependent, time-independent and independent of the contract duration. This is a major drawback since, as seen in Section 2.2, it would underestimate the stock level needed to meet the contract at the end of the contract duration. Such policies are widespread in the literature (Basten and van Houtum, 2014) and the most commonly used in practice, due to their ease of implementation in ERP systems. We use $J$ to denote the set of base stock levels $S$ under which, in steady-state, the average number of XLDs per period is lower than $K^{\mathrm{obj}} / T$ :

$J=\left\{S \mid 0 \leq S \leq N ; \sum_{d=S+1}^{N} \mathbb{P}\{X=d\}(d-S) \leq \frac{K^{o b j}}{T}\right\}$

Let $S_{1}^{*}$ denote the optimal base stock level for Heuristic 1:

$S_{1}^{*}=\underset{S \in J}{\operatorname{argmin}}\left\{\sum_{d=0}^{N} \mathbb{P}\{X=d\}\left[c^{h}(S-d)(S-d)^{+}+c^{e}(d-S)(d-S)^{+}\right]\right\}$.

The total expected costs of using this policy over the contract duration is given by $\bar{V}_{T}^{S_{1}^{*}}\left(K^{\mathrm{obj}}\right)$.

\subsection{Heuristic 2}

Similar to Heuristic 1, Heuristic 2 is state-independent and timeindependent. The difference is that it takes into account the finite contract duration. A similar heuristic, for different service measures, can be found in many finite horizon papers, see e.g. Al Hanbali and van der Heijden (2013) for example. Heuristic 2 optimizes the state-independent and time-independent base stock level. Hence, it is at least equally good as Heuristic 1 . Let $S_{2}^{*}$ denote the optimal base stock level for Heuristic 2:

$S_{2}^{*}=\underset{S \in\{0, \ldots, N\}}{\operatorname{argmin}}\left\{\bar{V}_{T}^{S}\left(K^{\mathrm{obj}}\right)\right\}$.

The expected costs of using this policy during the contract duration is given by $\bar{V}_{T}^{S_{2}^{*}}\left(K^{\mathrm{obj}}\right)$.

\subsection{Heuristic 3}

We define a state-dependent myopic policy. This policy is therefore time-independent and independent of the contract duration. For any given $K \in \mathscr{K}$, this policy sets a target stock level to minimize the oneperiod costs. Should a practitioner want to adjust stock levels based on contract performance, this policy would be one of the most intuitive ones. This policy is very risky though, as the costs of the further periods are not considered. Nevertheless, myopic policies represent an effective alternative to state-dependent policies as shown in Luo and Shang (2019) for example. Let $\hat{S}_{K}^{*}$ denote the base stock level that minimizes the one-period costs associated with fulfilling the contract for a given $K$. We have: 


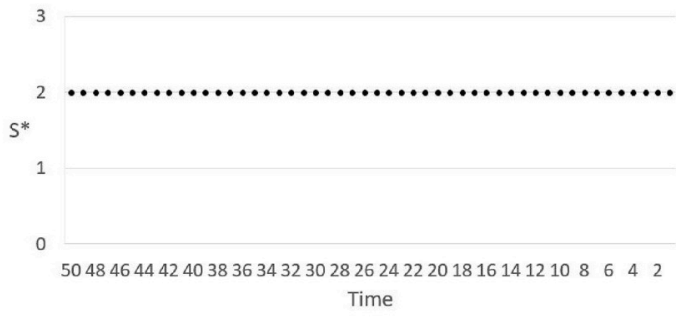

(a) $K=5$

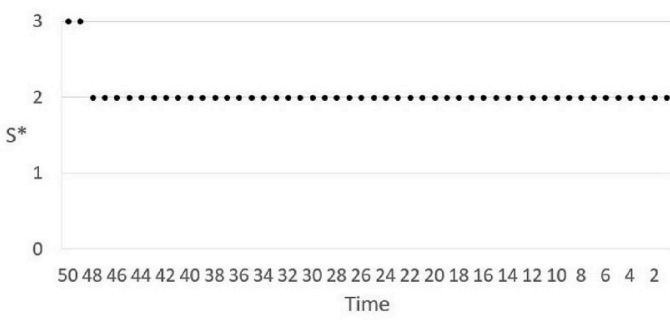

(c) $K=3$

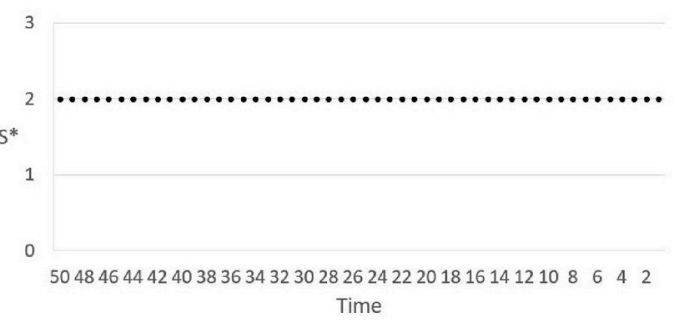

(b) $K=4$

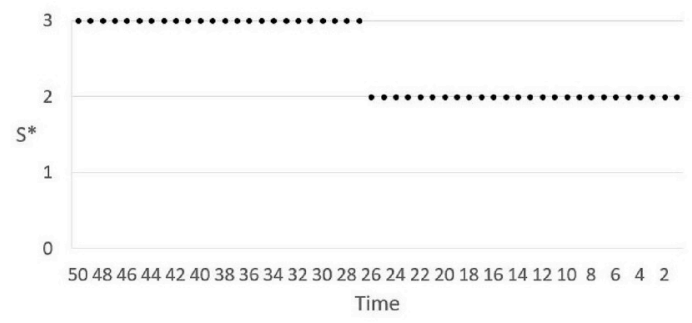

(d) $K=2$

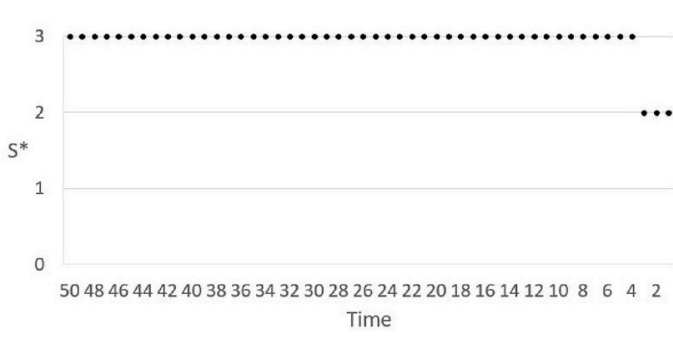

(e) $K=1$

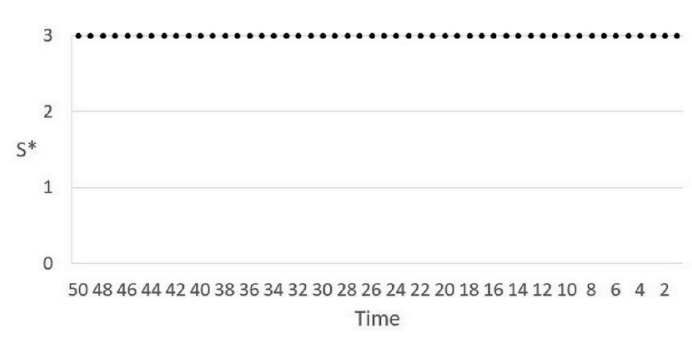

(f) $K=0$

Fig. 1. Behaviour of $S_{t}^{*}(K)$ for $N=10, K^{\mathrm{obj}}=5, p=0.1, c^{\mathrm{h}}=3, c^{\mathrm{e}}=30, c^{\mathrm{p}}=100$ and $T=50$

$\hat{S}_{K}^{*}=\underset{S \in\{0, \ldots, N\}}{\operatorname{argmin}}\{C(K, S)\}$, for $K \in \mathscr{K}$.

\section{Lemma 3. The optimal base stock level $\hat{S}_{K}^{*}$ is non-increasing in $K \in \mathscr{K}$.}

This is a direct consequence of $C(K, S)$, the direct expected costs function, being convex in $S$ and supermodular by Lemma 2 parts (iv) and $(v)$ respectively. At the beginning of period $T$, the on-hand stock is increased to $\hat{S}_{K^{\text {obj. }}}^{*}$ In each of the next periods, the on-hand stock is increased to $\hat{S}_{K}^{*}$. This is possible since, by Lemma $2, \hat{S}_{0}^{*} \geq \hat{S}_{1}^{*} \geq \ldots \geq \hat{S}_{K}^{*}$ obj. Let $\hat{V}_{t}(K)$ denote the expected costs obtained in $t$ periods under Heuristic 3. We have:

$$
\begin{aligned}
(K)= & C\left(K, \hat{S}_{K}^{*}\right)+\sum_{d=0}^{N} \mathbb{P}\{X=d\} \hat{V}_{t-1}((K \\
& \left.-(d-S)\left(\left(K-(d-S)^{+}\right)\right)^{+}\right), \text {for } t \in\{1, \ldots, T\}, K \in \mathscr{K}, \text { and } \\
& \hat{V}_{0}(K)=0, \text { for } K \in \mathscr{K} .
\end{aligned}
$$

The expected costs of using this policy during the contract duration is given by $\hat{V}_{T}\left(K^{\text {obj}}\right)$.

\section{Numerical study}

The purpose of this section is to quantify the cost benefits of the optimal policy over the heuristics. The numerical study also provides us some insights beyond the average cost differences and shows us for which situations we see the biggest differences. In Section 6.1, we explain how we designed our test bed. Section 6.2 provides the key insights gained.

\subsection{Design}

For our numerical experiment, we consider a contract length of $T=50$ weeks and we are particularly interested in varying the following variables. Varying the installed base size, $N$, is interesting to see the impact of the number of systems in scope of the contract. Varying $K^{\text {obj }}$ brings insights on how the service level agreement target setting influences stocking decisions. Our XLD service measure is intended to reduce the infrequent long downs. Therefore, we are interested in values of $K^{\mathrm{obj}}$ in the range $[1 ; N]$. The importance of taking into account the characteristics of spare parts is studied by Huiskonen (2001). In this experiment, we are most interested in the effects of the reliability and the price of the component. We are interested in lower values of $p$, i.e., $0<p \leq 0.1$. The probability of failure $p$ during one week is interesting since, within our range of $p$, the variance increases as $p$ increases while the coefficient of variation decreases as $p$ increases. The expectation here is to have a smaller optimality gap for less reliable systems. The 
Table 1

Test bed for the numerical experiment.

\begin{tabular}{|c|c|c|c|c|c|c|}
\hline$T$ & $N$ & $K^{\text {obj }}$ & $p$ & $c^{\mathrm{h}}$ & $c^{\mathrm{e}}$ & $c^{\mathrm{p}}$ \\
\hline (Weeks) & & & & (k€ per week) & (k€ per shipment) & (k€ per occurrence) \\
\hline 50 & {$[3 ; 9 ; 27]$} & {$\left[\frac{N}{3} ; \frac{2 N}{3} ; N\right]$} & {$[0.01 ; 0.05 ; 0.1]$} & {$[0.1 ; 1 ; 10]$} & 10 & 100 \\
\hline
\end{tabular}

Table 2

Summary of the results of the numerical experiment.

\begin{tabular}{|c|c|c|c|c|c|c|c|}
\hline & & \multicolumn{2}{|c|}{ Gap Heuristic 1} & \multicolumn{2}{|c|}{ Gap Heuristic 2} & \multicolumn{2}{|c|}{ Gap Heuristic 3} \\
\hline & & Average & Max & Average & Max & Average & $\operatorname{Max}$ \\
\hline \multirow[t]{6}{*}{$N$} & 3 & $203.4 \%$ & $1940 \%$ & $12.2 \%$ & $96 \%$ & $2.2 \%$ & $22 \%$ \\
\hline & 9 & $966.3 \%$ & $8279 \%$ & $3.4 \%$ & $21 \%$ & $6.8 \%$ & $49 \%$ \\
\hline & 27 & $661.7 \%$ & $7061 \%$ & $4.8 \%$ & $53 \%$ & $4.6 \%$ & $35 \%$ \\
\hline & & $850.0 \%$ & $8279 \%$ & $6.5 \%$ & $53 \%$ & $4.9 \%$ & $35 \%$ \\
\hline & & $563.4 \%$ & $6378 \%$ & $8.1 \%$ & $96 \%$ & $5.0 \%$ & $49 \%$ \\
\hline & $N$ & $418.0 \%$ & $4487 \%$ & $5.8 \%$ & $38 \%$ & $3.5 \%$ & $46 \%$ \\
\hline \multirow[t]{6}{*}{$p$} & 0.01 & $222.6 \%$ & $1940 \%$ & $9.8 \%$ & $96 \%$ & $0.5 \%$ & $12 \%$ \\
\hline & 0.05 & $208.3 \%$ & $1623 \%$ & $5.2 \%$ & $38 \%$ & $7.8 \%$ & $49 \%$ \\
\hline & 0.1 & $1400.4 \%$ & $8279 \%$ & $5.4 \%$ & $31 \%$ & $5.2 \%$ & $22 \%$ \\
\hline & 0.1 & $1396.5 \%$ & $8279 \%$ & $0.8 \%$ & $9 \%$ & $0.0 \%$ & $0 \%$ \\
\hline & 1 & $204.5 \%$ & $1153 \%$ & $10.8 \%$ & $96 \%$ & $0.3 \%$ & $5 \%$ \\
\hline & 10 & $230.3 \%$ & $1940 \%$ & $8.9 \%$ & $53 \%$ & $13.2 \%$ & $49 \%$ \\
\hline \multicolumn{2}{|c|}{ Total } & & $8279 \%$ & $6.8 \%$ & $96 \%$ & $4.5 \%$ & $49 \%$ \\
\hline
\end{tabular}

Table 3

Optimality gaps of 81 instances under the three heuristics.

\begin{tabular}{llll}
\hline & Heuristic 1 & Heuristic 2 & Heuristic 3 \\
\hline Optimal & 11 & 32 & 52 \\
$0 \%<$ optimality gap $\leq 5 \%$ & 10 & 24 & 14 \\
$5 \%<$ optimality gap $\leq 20 \%$ & 8 & 18 & 9 \\
$20 \%>$ optimality gap & 52 & 7 & 6 \\
\hline
\end{tabular}

holding costs, $c^{\mathrm{h}}$, are particularly relevant as different values reflect variation in the cost price of the component. We use only high value components in the test bed as it is more in line with the type of component subject to such contract (e.g., plane engines, landing gears). The emergency and penalty costs are kept constant. The values used in the test bed are inspired by the practice of ASML, a supplier of photo-lithography equipments for the semiconductor industry. The proposed test bed yields 81 different instances and is shown in Table 1.

\subsection{Results}

A summarized overview of the results is given in Table 2. The detailed results can be found in Appendix B. Heuristics 1 is, on average, $610 \%$ more expensive than the optimal policy. Even though Heuristic 1 performs poorly, it performs well in over a quarter of the cases with an optimality gap lower than $5 \%$ as can be seen in Table 3 . There are two main reasons behind the poor average performance of this heuristic. First, it never allows for the base stock level to be equal to zero. Second, being based on steady-state performance, it does not take into account the variation of the demand within the contract duration, resulting in too low base stock levels. Together, these cases account for 49 out of the 60 instances for which the optimality gap is higher than $5 \%$.

Heuristic 2 performs much better than Heuristic 1 with an average optimality gap of $6.8 \%$ confirming the insights of Section 2.2. Even though Heuristic 2 can have optimality gaps up to $96 \%$, the base stock levels it sets, are equal to $S_{T}^{*}\left(K^{\text {obj}}\right)$ in 70 out of the 81 instances. Interestingly, it is also the case for the instance with the highest optimality gap.

Heuristic 3 is on average $4.5 \%$ more expensive than the optimal policy. Heuristic 3 having the smallest average optimality gap shows that a myopic policy could be an effective alternative to a state-dependent policy. The maximum optimality gap is $49 \%$ and occurs when nine systems are considered, $K^{\mathrm{obj}}=2 N / 3, p=0.05$ and $c^{h}=10$. This situation is very realistic in a setting such as the one of ASML and such an optimality gap would be too high for an implementation in practice. On the other hand, as shown in Table 3, 66 out of the 81 instances have an optimality gap of at most $5 \%$. In other words, in $81 \%$ of the cases, this heuristic could be implemented. The 15 instances where the gap is higher than $5 \%$, all occur for $c^{h}=10$. In all these cases, the base stock level set by Heuristic 3 is lower than the optimal one. This is a known pitfall of the myopic policy that optimizes for the one-period costs without considering the remaining periods. In the practice of ASML, such expensive modules are seldom and have low failure rates. For the instances where $c^{h}=10$ and $p=0.01$, the average optimality gap of Heuristic 3 is $1.4 \%$.

The numerical results show that the optimal policy is significantly better than both Heuristic 2 and Heuristic 3 for multiple instances. This shows the value of taking into account the remaining contract duration as well as the current contract performance in stocking decisions. Heuristics 2 and 3 building on the former and the latter respectively perform relatively well. Heuristic 3 does perform the best though with the lowest average optimality gap, the lowest maximum gap and being optimal in $64 \%$ of the cases.

\section{Conclusion}

In this paper, we introduce the XLD service measure to answer the need for reducing harmful infrequent long outages. Using a finite horizon Markov decision process, we prove that the optimal policy is a state-dependent, time-dependent base stock policy. Using a numerical study, we compare the optimal policy with heuristics. Our Heuristic 3, a myopic heuristic, is the best performing heuristic but can still have high optimality gaps in some cases. This shows that significant savings can be made by taking into account the current contract performance and the remaining contract duration in spare parts stocking decisions. These savings can be translated, for the OEM, in either higher margin or a more competitive service contract price.

Interesting for further research would be the extension to a multiitem model and defining better performing heuristics.

\section{Acknowledgements}

The authors thank ASML Netherlands B.V., the Netherlands for the full support of this research.

\section{Appendices}

\section{A Proofs}

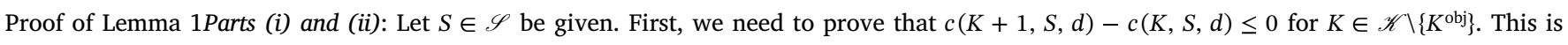


shown as follows:

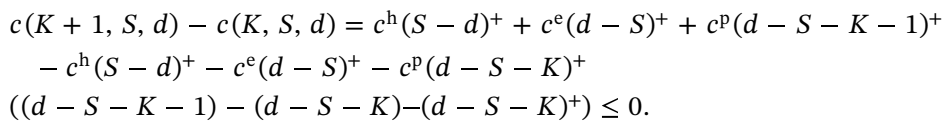

Next, we need to prove that $c(K, S, d)-c(K+1, S, d) \leq c^{\mathrm{p}}$ for $K \in \mathscr{K} \backslash\left\{K^{\mathrm{obj}}\right\}$. This property is obtained along the same lines.

Parts (iii) and (iv): The holding costs are given by $c^{\mathrm{h}}(S-d)^{+}$. This function is piecewise linear, non-increasing in $S$ and constant in $K$. Therefore, the holding costs are convex in $K$ for a given $S$ and in $S$ for a given $K$. The emergency costs are given by $c^{\mathrm{e}}(d-S)^{+}$. This function is piecewise linear, non-decreasing in $S$ and constant in $K$. The emergency costs are thus convex in $K$ and in $S$. The penalty costs are given by $c^{\mathrm{p}}(d-S-K)^{+}$. This function is piecewise linear, non-decreasing in $S$ and $K$. So, the penalty costs are convex in $K$ and in $S . c(K, S, d)$ is the summation of functions that are convex both in $K$ and $S$, and is therefore also convex in $K$ and $S$.

Part (v): We need to prove that $c(K+1, S+1, d)+c(K, S, d)-c(K+1, S, d)-c(K, S+1, d) \geq 0$ for $K \in \mathscr{K} \backslash\left\{K^{\text {obj }}\right\}$ and $S \in \mathscr{S} \backslash\{N\}$. This is shown as follows (use Lemma 1(iii) for the last step):

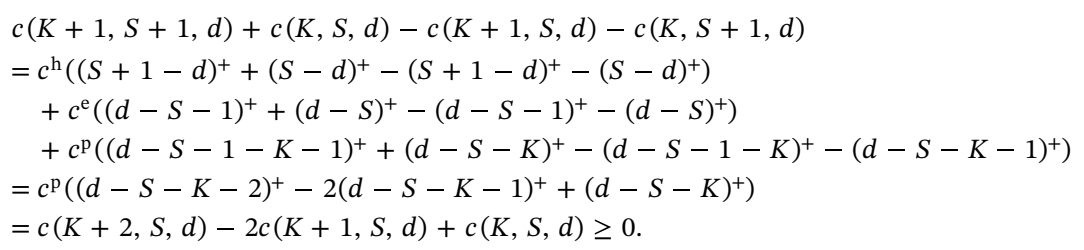

Part (vi): We need to prove that $c(K, S+2, d)-c(K, S+1, d)-c(K+1, S+1, d)+c(K+1, S, d) \geq 0$ for $K \in \mathscr{K} \backslash\left\{K^{\text {obj }}\right\} \quad$ and $S \in \mathscr{S} \backslash\{N-1, N\}$. This is shown as follows (use the convexity of the functions $(S-d)^{+}$and $(d-S)^{+}$for the last step):

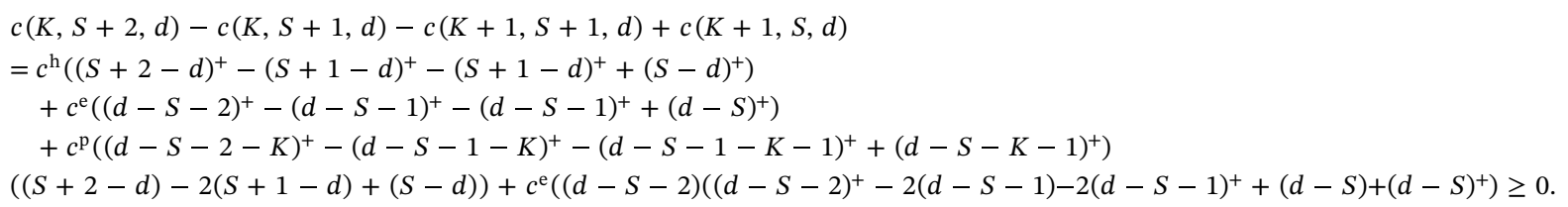

Part (vii): We need to prove that $c(K+2, S, d)-c(K+1, S, d)-c(K+1, S+1, d)+c(K, S+1, d) \geq 0$ for $K \in \mathscr{K} \backslash\left\{K^{\mathrm{obj}}-1, K^{\mathrm{obj}}\right\}$ and $S \in \mathscr{S} \backslash\{N\}$. This is shown as follows:

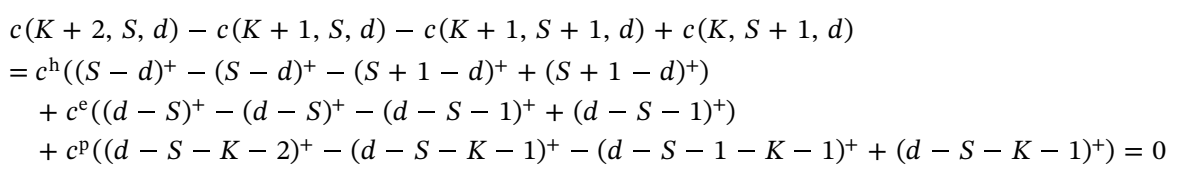

Proof of Lemma 2. $C(K, S)=\sum_{d=0}^{N} \mathbb{P}\{X=d\} c(K, S, d)$, i.e., $C(K, S)$ is the summation with positive weights of the functions $c(K, S, d)$. Therefore, all the properties that hold for $c(K, S, d)$ also hold for $C(K, S)$.

Proof of Theorem 1. We proceed by induction to $t$. For $t=0, V_{t}(K, I)=0$ for all $K \in \mathscr{K}$ and $I \in \mathscr{S}$ and thus, part B holds for $t=0$. Let us now assume that part B holds for a given $t \in\{0, \ldots, T-1\}$. We need to prove that parts A and B holds for $t+1$.

Part A(i): We prove that $\tilde{V}_{t+1}(K, S)-\tilde{V}_{t+1}(K+1, S) \geq 0$, for $K \in \mathscr{K} \backslash\left\{K^{\text {obj }}\right\}$ and $S \in \mathscr{S}$ :

$$
\begin{aligned}
& (K, S)-\tilde{V}_{t+1}(K+1, S)=C(K, S)+\sum_{d=0} N_{\mathbb{P}}\{X=d\} V_{t}\left(\left(K-(d-S)\left(\left(K-(d-S)^{+}\right)\right)^{+},(S-d),(S-d)^{+}\right)-C(K+1, S)\right. \\
& -\sum_{d=0} N_{\mathbb{P}}\{X=d\} V_{t}\left(\left(K+1-(d-S)\left(\left(K+1-(d-S)^{+}\right)\right)^{+},(S-d),(S-d)^{+}\right)\right.
\end{aligned}
$$

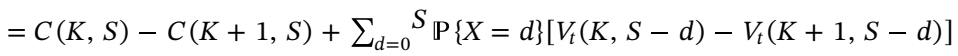

$$
\begin{aligned}
& \mathbb{P}\{X=d\}\left[V _ { t } \left((K-d+S)\left((K-d+S)^{+}, 0\right)-V_{t}\left((K+1-d+S)\left((K+1-d+S)^{+}, 0\right)\right] \geq 0 .\right.\right.
\end{aligned}
$$

The inequality follows from Lemma 2(i), Theorem 1.B $(i v)$ and 1.B $(v)$.

Part A (ii): We now prove that $\tilde{V}_{t+1}(K, S)-\tilde{V}_{t+1}(K+1, S) \leq c^{\mathrm{p}}$, for $K \in \mathscr{K} \backslash\left\{K^{\mathrm{obj}}\right\}$ and $S \in \mathscr{S}$.

$$
\begin{aligned}
& (K, S)-\tilde{V}_{t+1}(K+1, S)=C(K, S)+\sum_{d=0} N_{\mathbb{P}}\{X=d\} V_{t}\left(\left(K-(d-S)\left(\left(K-(d-S)^{+}\right)\right)^{+},(S-d),(S-d)^{+}\right)\right. \\
& C K S P\{X=d\} V_{t}\left(\left(K+1-(d-S)\left(\left(K+1-(d-S)^{+}\right)\right)^{+},(S-d),(S-d)^{+}\right)\right. \\
& \mathbb{P}\{X=d\}\left[c(K, S, d)+V_{t}\left(\left(K-(d-S)\left(\left(K-(d-S)^{+}\right)\right)^{+},(S-d),(S-d)^{+}\right)\right.\right. \\
& \left.-c(K+1, S, d)-V_{t}\left(\left(K+1-(d-S)^{+}\right)^{+},(S-d)^{+}\right)\right] \\
& \mathbb{P}\{X=d\}\left[c^{\mathrm{h}}(S-d)(S-d)^{+}+c^{\mathrm{e}}(d-S)(d-S)^{+}+c^{\mathrm{p}}(d-S-K)(d-S-K)^{+}+V_{t}\left(\left(K-(d-S)\left(\left(K-(d-S)^{+}\right)\right)^{+},(S-d),(S-d)^{+}\right)\right.\right. \\
& \left.-c^{\mathrm{h}}(S-d)^{+}-c^{\mathrm{e}}(d-S)^{+}-c^{\mathrm{p}}(d-S-K-1)^{+}-V_{t}\left(\left(K+1-(d-S)^{+}\right)^{+},(S-d)^{+}\right)\right] \\
& \mathbb{P}\{X=d\}\left[c^{\mathrm{p}}(d-S-K)(d-S-K)^{+}-c^{\mathrm{p}}(d-S-K-1)^{+}\right. \\
& \left.+V_{t}\left(\left(K-(d-S)^{+}\right)^{+},(S-d)^{+}\right)-V_{t}\left(\left(K+1-(d-S)^{+}\right)^{+},(S-d)^{+}\right)\right]
\end{aligned}
$$

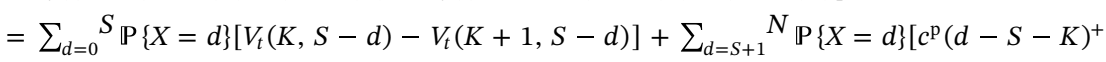

$$
\begin{aligned}
& \left.-c^{\mathrm{p}}(d-S-K-1)^{+}+V_{t}\left((K-d+S)^{+}, 0\right)-V_{t}\left((K+1-d+S)^{+}, 0\right)\right] \\
& \sum_{d=0}^{S} \mathbb{P}\{X=d\}\left[V_{t}(K, S-d)-V_{t}(K+1, S-d)\right] \leq \sum_{d=0}^{S} \mathbb{P}\{X=d\} c^{\mathrm{p}}
\end{aligned}
$$


by Theorem 1.B $(v)$. For the second part of the expression we have two cases. First if $S+K \geq N$, it holds that $(d-S-K)^{+}=0$, i.e., no penalty costs can be incurred. We have (use Theorem 1.B(vi) for the last step):

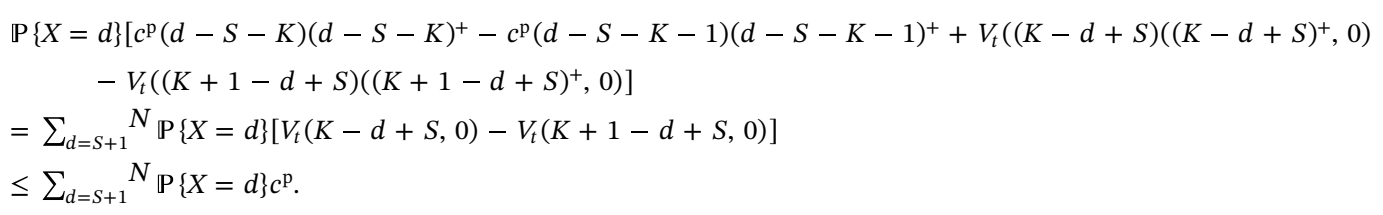

Next, if $S+K<N$, we have (use Theorem 1.B(vi) for the last step):

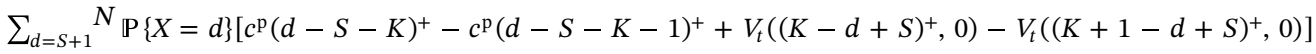

$$
\begin{aligned}
& =\sum_{d=S+1} S+K_{\mathbb{P}}\{X=d\}\left[V_{t}(K-d+S, 0)-V_{t}(K+1-d+S, 0)\right]
\end{aligned}
$$

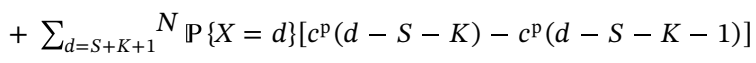

$$
\begin{aligned}
& \leq \sum_{d=S+1} N_{\mathbb{P}}\{X=d\} c^{\mathrm{p}} \text {. }
\end{aligned}
$$

Since it is true for all cases, we have $\tilde{V}_{t+1}(K, S)-\tilde{V}_{t+1}(K+1, S) \leq \sum_{d=0}^{S} \mathbb{P}\{X=d\} c^{\mathrm{p}}+\sum_{d=S+1}^{N} c^{\mathrm{p}}=c^{\mathrm{p}}$.

Part A(iii): We need to prove that $\tilde{V}_{t+1}(K, S+2)-\tilde{V}_{t+1}(K+1, S+1)-\tilde{V}_{t+1}(K, S+1)+\tilde{V}_{t+1}(K+1, S) \geq 0$, for $K \in \mathscr{K} \backslash\left\{K^{\text {obj }}\right\}$ and $S \in \mathscr{S} \backslash\{N-1, N\}$. We have:

$$
\begin{aligned}
& \tilde{V}_{t+1}(K, S+2)-\tilde{V}_{t+1}(K+1, S+1)-\tilde{V}_{t+1}(K, S+1)+\tilde{V}_{t+1}(K+1, S) \\
& =C(K, S+2)-C(K+1, S+1)-C(K, S+1)+C(K+1, S)+\sum_{d=0} N_{\mathbb{P}}\{X=d\}[ \\
& V_{t}\left(\left(K-(d-S-2)^{+}\right)^{+},(S+2-d)^{+}\right)-V_{t}\left(\left(K+1-(d-S-1)^{+}\right)^{+},(S+1-d)^{+}\right) \\
& \left.-V_{t}\left(\left(K-(d-S-1)^{+}\right)^{+},(S+1-d)^{+}\right)+V_{t}\left(\left(K+1-(d-S)^{+}\right)^{+},(S-d)^{+}\right)\right] \\
& =C(K, S+2)-C(K+1, S+1)-C(K, S+1)+C(K+1, S)
\end{aligned}
$$

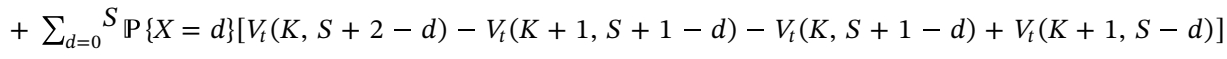

$$
\begin{aligned}
& +\mathbb{P}\{X=S+1\}\left[V_{t}(K, 1)-V_{t}(K+1,0)-V_{t}(K, 0)+V_{t}(K, 0)\right] \\
& \mathbb{P}\{X=d\}\left[V _ { t } \left((K-d+S+2)\left((K-d+S+2)^{+}, 0\right)-V_{t}\left((K+2-d+S)\left((K+2-d+S)^{+}, 0\right)\right.\right.\right. \\
& \left.((K-d+S+1), 0)+V_{t}(K+1-d+S)(K+1-d+S)^{+}, 0\right)
\end{aligned}
$$

We study each term separately:

- $C(K, S+2)-C(K+1, S+1)-C(K, S+1)+C(K+1, S) \geq 0$ by Lemma $1($ iv $)$,

- $\sum_{d=0}^{S} \mathbb{P}\{X=d\}\left[V_{t}(K, S+2-d)-V_{t}(K+1, S+1-d)-V_{t}(K, S+1-d)+V_{t}(K+1, S-d)\right] \geq 0$ by Theorem $1 . \mathrm{B}(v i i)$ and the summation with positive weights.

- $\mathrm{P}\{X=S+1\}\left[V_{t}(K, 1)-V_{t}(K+1,0)-V_{t}(K, 0)+V_{t}(K, 0)\right] \geq 0$ by Theorem 1.B(iv) and Theorem 1.B $(v)$.

$$
\begin{aligned}
\sum_{d=S+2}^{N} \mathbb{P}\{X= & d\}\left[V _ { t } \left((K-d+S+2)\left((K-d+S+2)^{+}, 0\right)-V_{t}\left((K+2-d+S)\left((K+2-d+S)^{+}, 0\right)-V_{t}\left((K-d+S+1)\left((K-d+S+1)^{+}, 0\right) .\right.\right.\right.\right. \\
& \left.+V_{t}(K+1-d+S)(K+1-d+S)^{+}, 0\right)
\end{aligned}
$$

Therefore, $\tilde{V}_{t+1}(K, S)$ is superconvex in $S$ for a given $K$.

Part A (iv): We need to prove that $\tilde{V}_{t+1}(K+2, S)-\tilde{V}_{t+1}(K+1, S+1)-\tilde{V}_{t+1}(K+1, S)+\tilde{V}_{t+1}(K, S+1) \geq 0$, for $K \in \mathscr{K} \backslash\left\{K^{\mathrm{obj}}-1, K^{\mathrm{obj}}\right\}$ and $S \in \mathscr{S} \backslash\{N\}$. We have:

$$
\begin{aligned}
& \tilde{V}_{t+1}(K+2, S)-\tilde{V}_{t+1}(K+1, S+1)-\tilde{V}_{t+1}(K+1, S)+\tilde{V}_{t+1}(K, S+1) \\
& =C(K+2, S)-C(K+1, S+1)-C(K+1, S)+C(K, S+1)+\sum_{d=0} N_{\mathbb{P}}\{X=d\}[ \\
& V_{t}\left(\left(K+2-(d-S)^{+}\right)^{+},(S-d)^{+}\right)-V_{t}\left(\left(K+1-(d-S-1)^{+}\right)^{+},(S+1-d)^{+}\right) \\
& \left.-V_{t}\left(\left(K+1-(d-S)^{+}\right)^{+},(S-d)^{+}\right)+V_{t}\left(\left(K-(d-S-1)^{+}\right)^{+},(S+1-d)^{+}\right)\right] \\
& =C(K+2, S)-C(K+1, S+1)-C(K+1, S)+C(K, S+1)
\end{aligned}
$$

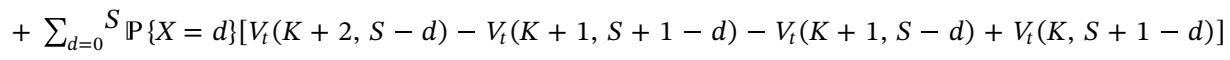

$$
\begin{aligned}
& \mathbb{P}\{X=d\}\left[V_{t}\left((K+2-d+S)\left((K+2-d+S)^{+}, 0\right)-V_{t}(K+1-d+S+1)(K+1-d+S+1)^{+}, 0\right)\right. \\
& \left.(K+1-d+S), 0)+V_{t}(K-d+S+1)(K-d+S+1)^{+}, 0\right) \\
& =C(K+2, S)-C(K+1, S+1)-C(K+1, S)+C(K, S+1)
\end{aligned}
$$

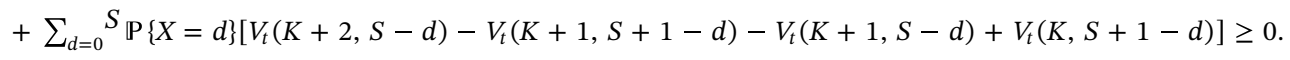

The last step follows by Lemma $1(v)$, Theorem 1.B(viii) and the summation with positive weights.

Part A(v): We need to prove that $\tilde{V}_{t+1}(K+1, S+1)-\tilde{V}_{t+1}(K+1, S)-\tilde{V}_{t+1}(K, S+1)+\tilde{V}_{t+1}(K, S) \geq 0$, for $K \in \mathscr{K} \backslash\left\{K^{\text {obj }}\right\}$ and $S \in \mathscr{S} \backslash\{N\}$. We have: 
$\tilde{V}_{t+1}(K+1, S+1)-\tilde{V}_{t+1}(K+1, S)-\tilde{V}_{t+1}(K, S+1)+\tilde{V}_{t+1}(K, S)$

$=C(K+1, S+1)-C(K+1, S)-C(K, S+1)+C(K, S)$

$\mathbb{P}\{X=d\}\left[V_{t}\left(\left(K+1-(d-S-1)\left(\left(K+1-(d-S-1)^{+}\right)\right)^{+},(S+1-d),(S+1-d)^{+}\right)\right.\right.$

$-V_{t}\left(\left(K+1-(d-S)\left(\left(K+1-(d-S)^{+}\right)\right)^{+},(S-d),(S-d)^{+}\right)\right.$

$\left.-V_{t}\left(\left(K-(d-S-1)^{+}\right)^{+},(S+1-d)^{+}\right)+V_{t}\left(\left(K-(d-S)^{+}\right)^{+},(S-d)^{+}\right)\right]$

$=C(K+1, S+1)-C(K+1, S)-C(K, S+1)+C(K, S)$

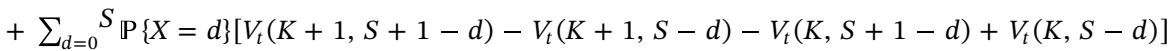

$\mathbb{P}\{X=d\}\left[V_{t}\left((K+1-d+S+1)\left((K+1-d+S+1)^{+}, 0\right)-V_{t}\left((K+1-d+S)\left((K+1-d+S)^{+}, 0\right)\right.\right.\right.$

$\left.-V_{t}\left((K-d+S+1)^{+}, 0\right)+V_{t}\left((K-d+S)^{+}, 0\right)\right]$

$=C(K+1, S+1)-C(K+1, S)-C(K, S+1)+C(K, S)$

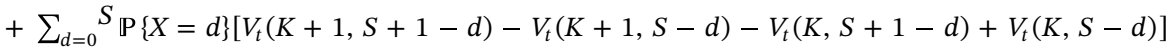

$\mathbb{P}\{X=d\}\left[V_{t}\left((K+2-d+S)\left((K+2-d+S)^{+}, 0\right)-2 V_{t}\left((K+1-d+S)\left((K+1-d+S)^{+}, 0\right)+V_{t}\left((K-d+S)\left((K-d+S)^{+}, 0\right)\right]\right.\right.\right.$

$=\sum_{d=0} S_{\mathbb{P}}\{X=d\}[c(K+1, S+1, d)-c(K+1, S, d)-c(K, S+1, d)+c(K, S, d)$

$\left.+V_{t}(K+1, S+1-d)-V_{t}(K+1, S-d)-V_{t}(K, S+1-d)+V_{t}(K, S-d)\right]$

$+\sum_{d=S+1} N_{\mathbb{P}}\{X=d\}[c(K+1, S+1, d)-c(K+1, S, d)-c(K, S+1, d)+c(K, S, d)$

$\left.+V_{t}\left((K+2-d+S)^{+}, 0\right)-2 V_{t}\left((K+1-d+S)^{+}, 0\right)+V_{t}\left((K-d+S)^{+}, 0\right)\right]$

We study each term separately. For each $\quad d \in\{0, \ldots, S\}, \quad c(K+1, S+1, d)-c(K+1, S, d)-$ $c(K, S+1, d)+c(K, S, d)+V_{t}(K+1, S+1-d)-V_{t}(K+1, S-d)-V_{t}(K, S+1-d)+V_{t}(K, S-d) \geq 0$ by Lemma 1 (iii), by Theorem 1.B(ix). Therefore $\sum_{d=0}^{S} \mathbb{P}\{X=d\}\left[c(K+1, S+1, d)-c(K+1, S, d)-c(K, S+1, d)+c(K, S, d)+V_{t}(K+1, S+1-d)-V_{t}(K+1, S-d)-V_{t} 0\right.$, sum-

\section{$\left.(K, S+1-d)+V_{t}(K, S-d)\right] \geq$}

mation of positive elements with positive weights. Let $A(d)$ denote the part of the last term between squared brackets. We need to prove that, for $d \in\{S+1, \ldots, N\}, A(d)$ is nonnegative. We distinguish three demand cases, $S+1 \leq d<S+K+1, d=K+S+1$ and $K+S+1<d \leq N$. The first case is possible for $K<N-S-1, K=N-S-1$ and $K>N-S-1$. The second case is possible for $K<N-S-1$ and $K=N-S-1$. The third case is only possible for $K<N-S-1$. The different cases are summarized in the Table 4.

For the first row of Table 4, we have (use Lemma 1(iii) and Theorem 1.B $(x)$ for the last step):

$A(d)=c(K+1, S+1, d)-c(K+1, S, d)-c(K, S+1, d)+c(K, S, d)$

$+V_{t}(K+2-d+S, 0)-2 V_{t}(K+1-d+S, 0)+V_{t}(K-d+S, 0) \geq 0$.

For the second row of Table 4, we have (use Theorem 1.B(vi) for the last step):

$A(d)=c(K+1, S+1, d)-c(K+1, S, d)-c(K, S+1, d)+c(K, S, d)+V_{t}(1,0)-2 V_{t}(0,0)+V_{t}(0,0)$

$=c^{\mathrm{h}}(S+1-d)^{+}+c^{\mathrm{e}}(d-S-1)^{+}+c^{\mathrm{p}}(d-S-K-2)^{+}$

$-c^{\mathrm{h}}(S-d)^{+}-c^{\mathrm{e}}(d-S)^{+}-c^{\mathrm{p}}(d-S-K-1)^{+}$

$-c^{\mathrm{h}}(S+1-d)^{+}-c^{\mathrm{e}}(d-S-1)^{+}-c^{\mathrm{p}}(d-S-K-1)^{+}$

$+c^{\mathrm{h}}(S-d)^{+}+c^{\mathrm{e}}(d-S)^{+}+c^{\mathrm{p}}(d-S-K)^{+}+V_{t}(1,0)-2 V_{t}(0,0)+V_{t}(0,0)$

$=c^{\mathrm{p}}\left((d-S-K-2)^{+}-2 c^{\mathrm{p}}(d-S-K-1)^{+}+c^{\mathrm{p}}(d-S-K)^{+}\right)+V_{t}(1,0)-2 V_{t}(0,0)+V_{t}(0,0)$

$=c^{\mathrm{p}}+V_{t}(1,0)-V_{t}(0,0) \geq 0$.

For the third row of Table 4, we have (use Lemma 1(iii) for the last step):

$A(d)=c(K+1, S+1, d)-c(K+1, S, d)-c(K, S+1, d)+c(K, S, d)+V_{t}(0,0)-2 V_{t}(0,0)+V_{t}(0,0)$

$=c(K+1, S+1, d)-c(K+1, S, d)-c(K, S+1, d)+c(K, S, d) \geq 0$.

Part A (vi): We need to prove that $\tilde{V}_{t+1}(K, S+2)-2 \tilde{V}_{t+1}(K, S+1)+\tilde{V}_{t+1}(K, S) \geq 0$, for $K \in \mathscr{K}$ and $S \in \mathscr{S} \backslash\{N\}$. For $K<K^{\text {obj }}$, we have (use Theorem 1.A (ii) and (iv) for the last step):

$\tilde{V}_{t+1}(K, S+2)-2 \tilde{V}_{t+1}(K, S+1)+\tilde{V}_{t+1}(K, S)$

$=\tilde{V}_{t+1}(K, S+2)-2 \tilde{V}_{t+1}(K, S+1)+\tilde{V}_{t+1}(K, S)$

$+\tilde{V}_{t+1}(K+1, S+1)-\tilde{V}_{t+1}(K+1, S+1)+\tilde{V}_{t+1}(K+1, S)-\tilde{V}_{t+1}(K+1, S)$

$=\tilde{V}_{t+1}(K, S+2)-\tilde{V}_{t+1}(K+1, S+1)-\tilde{V}_{t+1}(K, S+1)+\tilde{V}_{t+1}(K+1, S)$

$+\tilde{V}_{t+1}(K+1, S+1)-\tilde{V}_{t+1}(K+1, S)-\tilde{V}_{t+1}(K, S+1)+\tilde{V}_{t+1}(K, S) \geq 0$.

For $K=K^{\mathrm{obj}}$, we have (use Theorem 1.A(ii) and (iv) for the last step):

Table 4

Overview of the different cases.

\begin{tabular}{llll}
\hline & $K<N-S-1$ & $K=N-S-1$ & $K>N-S-1$ \\
\hline $1 . S+1 \leq d<S+K+1$ & $S+1 \leq d<N-1$ & $S+1 \leq d<N$ & $S+1 \leq d<N+1$ \\
$2 . d=S+K+1$ & $d=N-1$ & $d=N$ & NA \\
$3 . S+K+1<d \leq N$ & $d=N$ & NA & NA \\
\hline
\end{tabular}


$\tilde{V}_{t+1}(K, S+2)-2 \tilde{V}_{t+1}(K, S+1)+\tilde{V}_{t+1}(K, S)$

$=\tilde{V}_{t+1}(K, S+2)-2 \tilde{V}_{t+1}(K, S+1)+\tilde{V}_{t+1}(K, S)$

$+\tilde{V}_{t+1}(K-1, S+1)-\tilde{V}_{t+1}(K-1, S+1)+\tilde{V}_{t+1}(K-1, S+2)-\tilde{V}_{t+1}(K-1, S+2)$

$=\tilde{V}_{t+1}(K, S+2)-\tilde{V}_{t+1}(K-1, S+2)-\tilde{V}_{t+1}(K, S+1)+\tilde{V}_{t+1}(K-1, S+1)$

$+\tilde{V}_{t+1}(K-1, S+2)-\tilde{V}_{t+1}(K-1, S+1)-\tilde{V}_{t+1}(K, S+1)+\tilde{V}_{t+1}(K, S) \geq 0$.

Part A(vii): Similarly to part $(v), \tilde{V}_{t+1}(K, S)$ is superconvex in $K$ and supermodular by Theorem 1.A(viii) and Theorem 1. A(ix) respectively. Therefore, $\tilde{V}_{t+1}(K, S)$ is convex in $K \in \mathscr{K}$ for a given $S \in \mathscr{S}$.

Parts B(i) and (ii): By Theorem 1.A (vi), we have convexity of $\tilde{V}_{t}(K, S)$ in $S \in \mathscr{S}$. We know that the $S$ that minimizes $V_{t+1}(K, I)$ is independent of $I$, except that $I$ acts as a lower bound. We have:

$V_{t+1}(K, I)=\left\{\begin{array}{cc}\tilde{V}_{t+1}\left(K, S_{t+1}^{*}(K)\right), & \text { for } \quad 0 \leq I \leq S_{t+1}^{*}(K), \\ \tilde{V}_{t+1}(K, I), & \text { for } \quad I>S_{t+1}^{*}(K) .\end{array}\right.$

That means that $V_{t+1}(K, I)=V_{t+1}(K, I+1)$ up to $I=S_{t+1}^{*}(K)-1$, after which $V_{t+1}(K, I)$ will be increasing, convex in $I$, which concludes our Proof. Therefore, a state-dependant base stock policy is optimal in each time period.

Part B(iii): By Theorem 1.A(v), $\tilde{V}_{t+1}(K, S)$ is supermodular. Therefore, $\Delta_{S} \tilde{V}_{t+1}(K, S) \leq \Delta_{S} \tilde{V}_{t+1}(K+1, S)$ for all $S$ and $K$. As a consequence, $S_{t+1}^{*}(K) \geq S_{t+1}^{*}(K+1)$. We now need to prove that $S_{t+1}^{*}(K) \leq S_{t+1}^{*}(K+1)+1$. We need $\Delta_{S} \tilde{V}_{t+1}(K, S) \geq \Delta_{S} \tilde{V}_{t+1}(K+1, S-1)$ for all $S$ and $K$. We have (use Theorem 1.A (iii) for the last step):

$\Delta_{S} \tilde{V}_{t+1}(K, S)-\Delta_{S} \tilde{V}_{t+1}(K+1, S-1)$

$=\tilde{V}_{t+1}(K, S+1)-\tilde{V}_{t+1}(K, S)-\tilde{V}_{t+1}(K+1, S)+\tilde{V}_{t+1}(K+1, S-1) \geq 0$.

Part B(iv): Let $t \in\{0, \ldots, T-1\}$ and $K \in \mathscr{K}$ be given. For all $I \in \mathscr{S} \backslash\{N\}$ :

$V_{t+1}(K, I)=\min _{S \in\{I, \ldots, N\}} \tilde{V}_{t+1}(K, S) \leq \min _{S \in\{I+1, \ldots, N\}} \tilde{V}_{t+1}(K, S)=V_{t+1}(K, I+1)$.

Parts $B(v)$ and (vi): We prove that $V_{t+1}(K, I)-V_{t+1}(K+1, I) \geq 0$, for $K \in \mathscr{K} \backslash\left\{K^{\text {obj }\}}\right.$ and $I \in \mathscr{S}$. From Theorem 1.A(i), it follows that

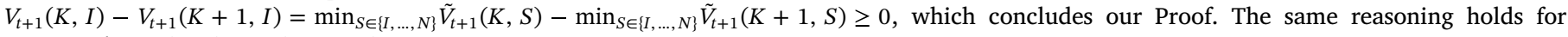
proving that $V_{t}(K, I)-V_{t}(K+1, I) \leq c^{\mathrm{p}}$.

Part B(vii): We need to prove that $V_{t+1}(K, I+2)-V_{t+1}(K, I+1)-V_{t+1}(K+1, I+1)+V_{t+1}(K+1, I) \geq 0$, for $K \in \mathscr{K} \backslash\left\{K^{\mathrm{obj}}\right\}$ and $I \in \mathscr{S} \backslash\{N-1, N\}$. We have two cases:

a. $S_{t+1}^{*}(K)=S_{t+1}^{*}(K+1)$

- If $I+2 \leq S_{t+1}^{*}(K)$, we have:

$V_{t+1}(K, I+2)-V_{t+1}(K, I+1)-V_{t+1}(K+1, I+1)+V_{t+1}(K+1, I)$

$=\tilde{V}_{t+1}\left(K, S_{t+1}^{*}(K)\right)-\tilde{V}_{t+1}\left(K, S_{t+1}^{*}(K)\right)-\tilde{V}_{t+1}\left(K+1, S_{t+1}^{*}(K)\right)+\tilde{V}_{t+1}\left(K+1, S_{t+1}^{*}(K)\right)=0$.

- If $I+1=S_{t+1}^{*}(K)$, we have (use Theorem 1.A(vi) and the optimality principle in the last step):

$V_{t+1}(K, I+2)-V_{t+1}(K, I+1)-V_{t+1}(K+1, I+1)+V_{t+1}(K+1, I)$

$=\tilde{V}_{t+1}\left(K, S_{t+1}^{*}(K)+1\right)-\tilde{V}_{t+1}\left(K, S_{t+1}^{*}(K)\right)-\tilde{V}_{t+1}\left(K+1, S_{t+1}^{*}(K)\right)+\tilde{V}_{t+1}\left(K+1, S_{t+1}^{*}(K)\right)$

$=\tilde{V}_{t+1}\left(K, S_{t+1}^{*}(K)+1\right)-\tilde{V}_{t+1}\left(K, S_{t+1}^{*}(K)\right) \geq 0$.

- If $I \geq S_{t+1}^{*}(K)$, we have (use Theorem 1.A(iii) in the last step):

$V_{t+1}(K, I+2)-V_{t+1}(K, I+1)-V_{t+1}(K+1, I+1)+V_{t+1}(K+1, I)$

$=\tilde{V}_{t+1}(K, I+2)-\tilde{V}_{t+1}(K, I+1)-\tilde{V}_{t+1}(K+1, I+1)+\tilde{V}_{t+1}(K+1, I) \geq 0$.

b. $S_{t+1}^{*}(K) \neq S_{t+1}^{*}(K+1)$. By Theorem 1.B(iii), it is equivalent to $S_{t+1}^{*}(K)=S_{t+1}^{*}(K+1)+1$

- If $I+2 \leq S_{t+1}^{*}(K)$, we have:

$V_{t+1}(K, I+2)-V_{t+1}(K, I+1)-V_{t+1}(K+1, I+1)+V_{t+1}(K+1, I)$

$=\tilde{V}_{t+1}\left(K, S_{t+1}^{*}(K)\right)-\tilde{V}_{t+1}\left(K, S_{t+1}^{*}(K)\right)-\tilde{V}_{t+1}\left(K+1, S_{t+1}^{*}(K+1)\right)+\tilde{V}_{t+1}\left(K+1, S_{t+1}^{*}(K+1)\right)=0$.

- If $I+1=S_{t+1}^{*}(K)$, we have (use Theorem 1.A(iii) in the last step):

$V_{t+1}(K, I+2)-V_{t+1}(K, I+1)-V_{t+1}(K+1, I+1)+V_{t+1}(K+1, I)$

$=\tilde{V}_{t+1}\left(K, S_{t+1}^{*}(K)+1\right)-\tilde{V}_{t+1}\left(K, S_{t+1}^{*}(K)\right)-\tilde{V}_{t+1}\left(K+1, S_{t+1}^{*}(K)\right)+\tilde{V}_{t+1}\left(K+1, S_{t+1}^{*}(K)-1\right) \geq 0$.

- If $I \geq S_{t+1}^{*}(K)$, we have (use Theorem 1.A (iii) in the last step):

$V_{t+1}(K, I+2)-V_{t+1}(K, I+1)-V_{t+1}(K+1, I+1)+V_{t+1}(K+1, I)$

$=\tilde{V}_{t+1}(K, I+2)-\tilde{V}_{t+1}(K, I+1)-\tilde{V}_{t+1}(K+1, I+1)+\tilde{V}_{t+1}(K+1, I) \geq 0$.

Part B (viii): We need to prove that $V_{t+1}(K+2, I)-V_{t+1}(K+1, I)-V_{t+1}(K+1, I+1)+V_{t+1}(K, I+1) \geq 0$, for $K \in \mathscr{K} \backslash\left\{K^{\mathrm{obj}}-1, K^{\mathrm{obj}}\right\}$ and .$I \in \mathscr{S} \backslash\{N\}$ We have four cases.

a. $S_{t+1}^{*}(K)=S_{t+1}^{*}(K+1)=S_{t+1}^{*}(K+2)$ :

- If $I \geq S_{t+1}^{*}(K)$, we have (use Theorem 1.A (iv) in the last step):

$V_{t+1}(K+2, I)-V_{t+1}(K+1, I)-V_{t+1}(K+1, I+1)+V_{t+1}(K, I+1)$

$=\tilde{V}_{t+1}(K+2, I)-\tilde{V}_{t+1}(K+1, I)-\tilde{V}_{t+1}(K+1, I+1)+\tilde{V}_{t+1}(K, I+1) \geq 0$. 
- If $I<S_{t+1}^{*}(K)$, we have (use Theorem 1.A(vii) in the last step):

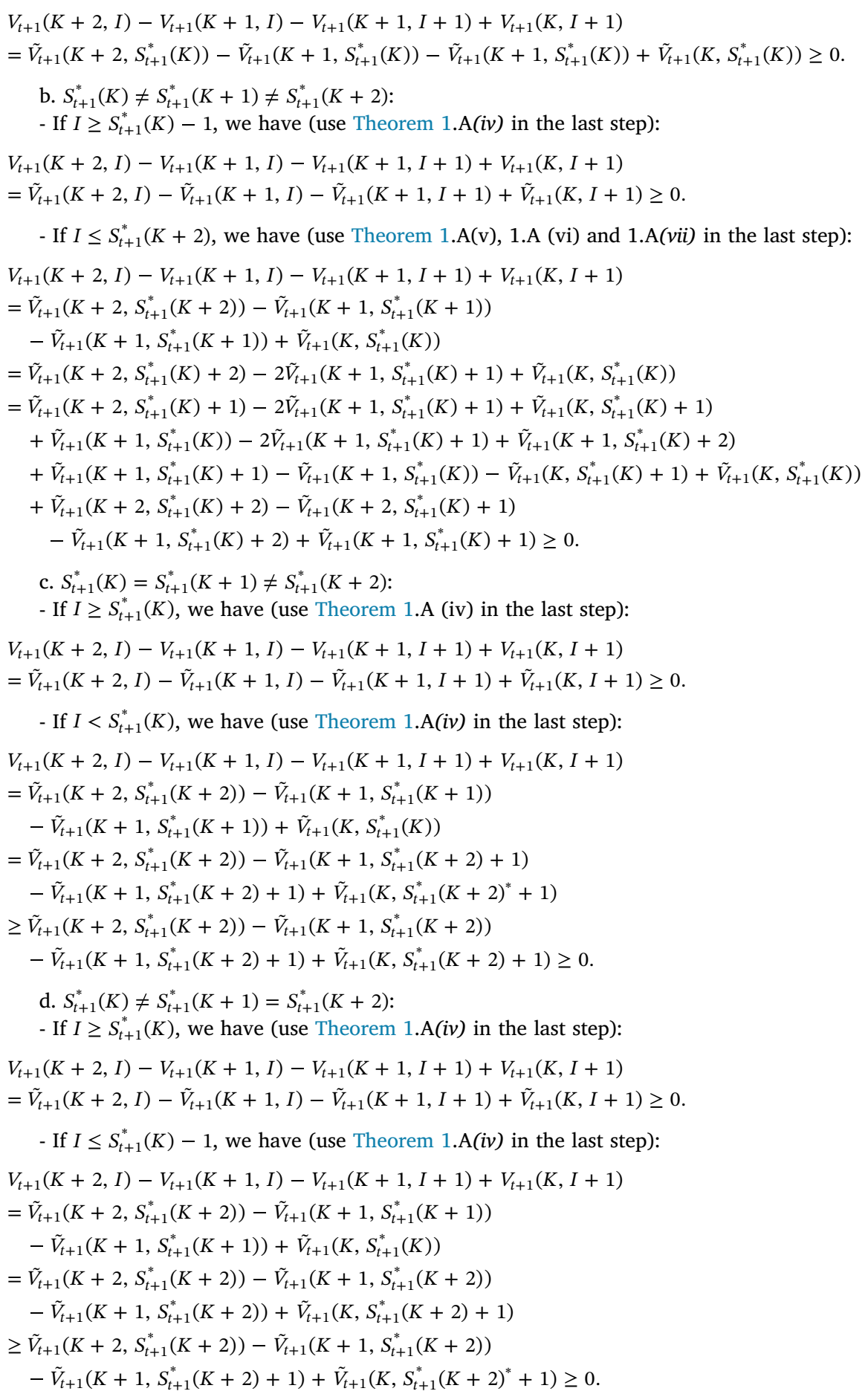

To conclude, for all the cases, the expression is greater or equal to zero. Therefore, $V_{t}(K, I)$ is superconvex in $K$ for all these cases which concludes our Proof.

Part B(ix): We need to prove that $V_{t+1}(K+1, I+1)-V_{t+1}(K+1, I)-V_{t+1}(K, I+1)+V_{t+1}(K, I) \geq 0$, for $K \in \mathscr{K} \backslash\left\{K^{\text {obj }}\right\}$ and $I \in \mathscr{S} \backslash\{N\}$. We have two cases:

a. $S_{t+1}^{*}(K)=S_{t+1}^{*}(K+1)$ :

- If $I \geq S_{t+1}^{*}(K)$, we have (use Theorem 1.A(v) in the last step):

$V_{t+1}(K+1, I+1)-V_{t+1}(K+1, I)-V_{t+1}(K, I+1)+V_{t+1}(K, I)$

$=\tilde{V}_{t+1}(K+1, I+1)-\tilde{V}_{t+1}(K+1, I)-\tilde{V}_{t+1}(K, I+1)+\tilde{V}_{t+1}(K, I) \geq 0$.

- If $I+1 \leq S_{t+1}^{*}(K)$, we have: 
$V_{t+1}(K+1, I+1)-V_{t+1}(K+1, I)-V_{t+1}(K, I+1)+V_{t+1}(K, I)$

$=\tilde{V}_{t+1}\left(K+1, S_{t+1}^{*}(K)\right)-\tilde{V}_{t+1}\left(K+1, S_{t+1}^{*}(K)\right)-\tilde{V}_{t+1}\left(K, S_{t+1}^{*}(K)\right)+\tilde{V}_{t+1}\left(K, S_{t+1}^{*}(K)\right)=0$.

b. $S_{t+1}^{*}(K) \neq S_{t+1}^{*}(K+1)$ :

- If $I \geq S_{t+1}^{*}(K)$, we have (use Theorem 1.A(v) in the last step):

$V_{t+1}(K+1, I+1)-V_{t+1}(K+1, I)-V_{t+1}(K, I+1)+V_{t+1}(K, I)$

$=\tilde{V}_{t+1}(K+1, I+1)-\tilde{V}_{t+1}(K+1, I)-\tilde{V}_{t+1}(K, I+1)+\tilde{V}_{t+1}(K, I) \geq 0$.

- If $I<S_{t+1}^{*}(K+1)$, we have:

$V_{t+1}(K+1, I+1)-V_{t+1}(K+1, I)-V_{t+1}(K, I+1)+V_{t+1}(K, I)$

$=\tilde{V}_{t+1}\left(K+1, S_{t+1}^{*}(K)\right)-\tilde{V}_{t+1}\left(K+1, S_{t+1}^{*}(K)\right)-\tilde{V}_{t+1}\left(K, S_{t+1}^{*}(K)\right)+\tilde{V}_{t+1}\left(K, S_{t+1}^{*}(K)\right)=0$

- If $I=S_{t+1}^{*}(K+1)=S_{t+1}^{*}(K)-1$, we have (use the optimality principle for the last step):

$V_{t+1}(K+1, I+1)-V_{t+1}(K+1, I)-V_{t+1}(K, I+1)+V_{t+1}(K, I)$

$=\tilde{V}_{t+1}\left(K+1, S_{t+1}^{*}(K+1)+1\right)-\tilde{V}_{t+1}\left(K+1, S_{t+1}^{*}(K+1)-\tilde{V}_{t+1}\left(K, S_{t+1}^{*}(K)\right)+\tilde{V}_{t+1}\left(K, S_{t+1}^{*}(K)\right) \geq 0\right.$.

$V_{t+1}(K+1, I+1)-V_{t+1}(K+1, I)-V_{t+1}(K, I+1)+V_{t+1}(K, I) \geq 0$ in all the cases, thus $V_{t}(K, I)$ is supermodular.

Part $\mathrm{B}(x)$ : Since $V_{t}(K, I)$ is superconvex in $K$ and supermodular, it is convex in $K$.

$B$ Results of numerical study.

\begin{tabular}{|c|c|c|c|c|c|c|c|c|c|c|c|c|c|c|c|}
\hline \multirow[t]{2}{*}{$N$} & \multirow[t]{2}{*}{ K } & \multirow{2}{*}{$\frac{K}{N}$} & \multirow[t]{2}{*}{$p$} & \multirow[t]{2}{*}{$c^{\mathrm{h}}$} & \multicolumn{2}{|l|}{ Optimal } & \multicolumn{3}{|c|}{ Heuristic 1} & \multicolumn{3}{|c|}{ Heuristic 2} & \multicolumn{3}{|c|}{ Heuristic 3} \\
\hline & & & & & $S_{T}^{*}\left(K^{\mathrm{obj}}\right)$ & Cost & $S_{1}^{*}$ & Cost & Gap & $S_{2}^{*}$ & Cost & Gap & $\hat{S}_{K^{\text {obj }}}^{*}$ & Cost & Gap \\
\hline 3 & 1 & $\mathrm{~N} / 3$ & 0.01 & 0.1 & 1 & 5.0 & 1 & 5.0 & $0.0 \%$ & 1 & 5.0 & $0.0 \%$ & 1 & 5.0 & $0.0 \%$ \\
\hline 3 & 2 & $\begin{array}{l}2 \mathrm{~N} / \\
3\end{array}$ & 0.01 & 0.1 & 1 & 5.0 & 1 & 5.0 & $0.0 \%$ & 1 & 5.0 & $0.0 \%$ & 1 & 5.0 & $0.0 \%$ \\
\hline 3 & 3 & $\mathrm{~N}$ & 0.01 & 0.1 & 1 & 5.0 & 1 & 5.0 & $0.0 \%$ & 1 & 5.0 & $0.0 \%$ & 1 & 5.0 & $0.0 \%$ \\
\hline 3 & 1 & $\mathrm{~N} / 3$ & 0.01 & 1 & 0 & 32.5 & 1 & 48.7 & $49.7 \%$ & 1 & 48.7 & $49.7 \%$ & 0 & 32.5 & $0.0 \%$ \\
\hline 3 & 2 & $\begin{array}{l}2 \mathrm{~N} / \\
3\end{array}$ & 0.01 & 1 & 0 & 21.9 & 1 & 48.7 & $122.6 \%$ & 0 & 42.8 & $96.0 \%$ & 0 & 21.9 & $0.0 \%$ \\
\hline 3 & 3 & $\mathrm{~N}$ & 0.01 & 1 & 0 & 17.2 & 1 & 48.7 & $182.7 \%$ & 0 & 23.8 & $38.2 \%$ & 0 & 17.2 & $0.0 \%$ \\
\hline 3 & 1 & $\mathrm{~N} / 3$ & 0.01 & 10 & 0 & 87.2 & 1 & 485.3 & $456.9 \%$ & 0 & 87.2 & $0.0 \%$ & 0 & 87.2 & $0.0 \%$ \\
\hline 3 & 2 & $\begin{array}{l}2 \mathrm{~N} / \\
3\end{array}$ & 0.01 & 10 & 0 & 42.8 & 1 & 485.3 & $1032.8 \%$ & 0 & 42.8 & $0.0 \%$ & 0 & 42.8 & $0.0 \%$ \\
\hline 3 & 3 & $\mathrm{~N}$ & 0.01 & 10 & 0 & 23.8 & 1 & 485.3 & $1939.9 \%$ & 0 & 23.8 & $0.0 \%$ & 0 & 23.8 & $0.0 \%$ \\
\hline 3 & 1 & $\mathrm{~N} / 3$ & 0.05 & 0.1 & 1 & 8.8 & 1 & 14.4 & $62.9 \%$ & 2 & 9.3 & $5.8 \%$ & 1 & 8.8 & $0.0 \%$ \\
\hline 3 & 2 & $\begin{array}{l}2 \mathrm{~N} / \\
3\end{array}$ & 0.05 & 0.1 & 1 & 8.1 & 1 & 8.8 & $8.5 \%$ & 1 & 8.8 & $8.5 \%$ & 1 & 8.1 & $0.0 \%$ \\
\hline 3 & 3 & $\mathrm{~N}$ & 0.05 & 0.1 & 1 & 8.0 & 1 & 8.1 & $0.9 \%$ & 1 & 8.1 & $0.9 \%$ & 1 & 8.0 & $0.0 \%$ \\
\hline 3 & 1 & $\mathrm{~N} / 3$ & 0.05 & 1 & 1 & 52.9 & 1 & 52.9 & $0.0 \%$ & 1 & 52.9 & $0.0 \%$ & 1 & 52.9 & $0.0 \%$ \\
\hline 3 & 2 & $\begin{array}{l}2 \mathrm{~N} / \\
3\end{array}$ & 0.05 & 1 & 1 & 47.4 & 1 & 47.4 & $0.0 \%$ & 1 & 47.4 & $0.0 \%$ & 1 & 47.4 & $0.0 \%$ \\
\hline 3 & 3 & $\mathrm{~N}$ & 0.05 & 1 & 1 & 46.6 & 1 & 46.6 & $0.0 \%$ & 1 & 46.6 & $0.0 \%$ & 1 & 46.6 & $0.0 \%$ \\
\hline 3 & 1 & $\mathrm{~N} / 3$ & 0.05 & 10 & 1 & 412.7 & 1 & 438.8 & $6.3 \%$ & 1 & 438.8 & $6.3 \%$ & 0 & 419.2 & $1.6 \%$ \\
\hline 3 & 2 & $\begin{array}{l}2 \mathrm{~N} / \\
3\end{array}$ & 0.05 & 10 & 0 & 362.6 & 1 & 433.2 & $19.5 \%$ & 1 & 433.2 & $19.5 \%$ & 0 & 366.7 & $1.1 \%$ \\
\hline 3 & 3 & $\mathrm{~N}$ & 0.05 & 10 & 0 & 312.6 & 1 & 432.5 & $38.4 \%$ & 1 & 432.5 & $38.4 \%$ & 0 & 315.1 & $0.8 \%$ \\
\hline 3 & 1 & $\mathrm{~N} / 3$ & 0.1 & 0.1 & 2 & 9.1 & 1 & 87.3 & $858.5 \%$ & 2 & 9.1 & $0.2 \%$ & 2 & 9.1 & $0.0 \%$ \\
\hline 3 & 2 & $\begin{array}{l}2 \mathrm{~N} / \\
3\end{array}$ & 0.1 & 0.1 & 2 & 9.0 & 1 & 45.1 & $400.1 \%$ & 2 & 9.0 & $0.0 \%$ & 2 & 9.0 & $0.0 \%$ \\
\hline 3 & 3 & $\mathrm{~N}$ & 0.1 & 0.1 & 2 & 9.0 & 1 & 26.9 & $198.6 \%$ & 2 & 9.0 & $0.0 \%$ & 2 & 9.0 & $0.0 \%$ \\
\hline 3 & 1 & $\mathrm{~N} / 3$ & 0.1 & 1 & 1 & 71.8 & 1 & 120.1 & $67.3 \%$ & 2 & 85.7 & $19.3 \%$ & 1 & 71.8 & $0.0 \%$ \\
\hline 3 & 2 & $\begin{array}{l}2 \mathrm{~N} / \\
3\end{array}$ & 0.1 & 1 & 1 & 59.3 & 1 & 77.9 & $31.2 \%$ & 1 & 77.9 & $31.2 \%$ & 1 & 59.3 & $0.0 \%$ \\
\hline 3 & 3 & $\mathrm{~N}$ & 0.1 & 1 & 1 & 53.8 & 1 & 59.7 & $11.0 \%$ & 1 & 59.7 & $11.0 \%$ & 1 & 53.8 & $0.0 \%$ \\
\hline 3 & 1 & $\mathrm{~N} / 3$ & 0.1 & 10 & 1 & 447.8 & 1 & 448.2 & $0.1 \%$ & 1 & 448.2 & $0.1 \%$ & 0 & 507.1 & $13.2 \%$ \\
\hline 3 & 2 & $\begin{array}{l}2 \mathrm{~N} / \\
3\end{array}$ & 0.1 & 10 & 1 & 401.5 & 1 & 405.9 & $1.1 \%$ & 1 & 405.9 & $1.1 \%$ & 0 & 481.6 & $19.9 \%$ \\
\hline 3 & 3 & $\mathrm{~N}$ & 0.1 & 10 & 1 & 374.0 & 1 & 387.8 & $3.7 \%$ & 1 & 387.8 & $3.7 \%$ & 0 & 456.7 & $22.1 \%$ \\
\hline 9 & 3 & $\mathrm{~N} / 3$ & 0.01 & 0.1 & 1 & 6.3 & 1 & 6.3 & $0.2 \%$ & 1 & 6.3 & $0.2 \%$ & 1 & 6.3 & $0.0 \%$ \\
\hline 9 & 6 & $\begin{array}{l}2 \mathrm{~N} / \\
3\end{array}$ & 0.01 & 0.1 & 1 & 6.3 & 1 & 6.3 & $0.0 \%$ & 1 & 6.3 & $0.0 \%$ & 1 & 6.3 & $0.0 \%$ \\
\hline 9 & 9 & $\mathrm{~N}$ & 0.01 & 0.1 & 1 & 6.3 & 1 & 6.3 & $0.0 \%$ & 1 & 6.3 & $0.0 \%$ & 1 & 6.3 & $0.0 \%$ \\
\hline 9 & 3 & $\mathrm{~N} / 3$ & 0.01 & 1 & 1 & 46.9 & 1 & 47.4 & $1.2 \%$ & 1 & 47.4 & $1.2 \%$ & 0 & 47.6 & $1.5 \%$ \\
\hline 9 & 6 & $\begin{array}{l}2 \mathrm{~N} / \\
3\end{array}$ & 0.01 & 1 & 0 & 45.5 & 1 & 47.4 & $4.2 \%$ & 1 & 47.4 & $4.2 \%$ & 0 & 45.6 & $0.2 \%$ \\
\hline 9 & 9 & $\mathrm{~N}$ & 0.01 & 1 & 0 & 45.1 & 1 & 47.4 & $5.3 \%$ & 1 & 47.4 & $5.3 \%$ & 0 & 45.1 & $0.0 \%$ \\
\hline 9 & 3 & $\mathrm{~N} / 3$ & 0.01 & 10 & 0 & 212.1 & 1 & 458.5 & $116.1 \%$ & 0 & 219.3 & $3.4 \%$ & 0 & 212.1 & $0.0 \%$ \\
\hline 9 & 6 & $\begin{array}{l}2 \mathrm{~N} / \\
3\end{array}$ & 0.01 & 10 & 0 & 75.6 & 1 & 458.5 & $506.2 \%$ & 0 & 76.9 & $1.7 \%$ & 0 & 75.6 & $0.0 \%$ \\
\hline 9 & 9 & $\mathrm{~N}$ & 0.01 & 10 & 0 & 47.5 & 1 & 458.5 & $864.9 \%$ & 0 & 47.6 & $0.2 \%$ & 0 & 47.5 & $0.0 \%$ \\
\hline 9 & 3 & $\mathrm{~N} / 3$ & 0.05 & 0.1 & 2 & 12.4 & 1 & 183.8 & $1383.5 \%$ & 2 & 12.7 & $2.5 \%$ & 2 & 12.4 & $0.0 \%$ \\
\hline
\end{tabular}




\begin{tabular}{|c|c|c|c|c|c|c|c|c|c|c|c|c|c|c|c|}
\hline 9 & 6 & $\begin{array}{l}2 \mathrm{~N} / \\
3\end{array}$ & 0.05 & 0.1 & 2 & 12.3 & 1 & 68.0 & $452.7 \%$ & 2 & 12.3 & $0.1 \%$ & 2 & 12.3 & $0.0 \%$ \\
\hline 9 & 9 & $\mathrm{~N}$ & 0.05 & 0.1 & 2 & 12.3 & 1 & 45.6 & $270.4 \%$ & 2 & 12.3 & $0.0 \%$ & 2 & 12.3 & $0.0 \%$ \\
\hline 9 & 3 & $\mathrm{~N} / 3$ & 0.05 & 1 & 2 & 80.7 & 1 & 212.2 & $163.1 \%$ & 2 & 82.9 & $2.7 \%$ & 1 & 84.4 & $4.6 \%$ \\
\hline 9 & 6 & $\begin{array}{l}2 \mathrm{~N} / \\
3\end{array}$ & 0.05 & 1 & 1 & 73.9 & 1 & 96.4 & $30.5 \%$ & 2 & 82.5 & $11.6 \%$ & 1 & 74.3 & $0.6 \%$ \\
\hline 9 & 9 & $\mathrm{~N}$ & 0.05 & 1 & 1 & 71.9 & 1 & 74.0 & $2.9 \%$ & 1 & 74.0 & $2.9 \%$ & 1 & 71.9 & $0.0 \%$ \\
\hline 9 & 3 & $\mathrm{~N} / 3$ & 0.05 & 10 & 1 & 495.5 & 1 & 495.8 & $0.1 \%$ & 1 & 495.8 & $0.1 \%$ & 0 & 627.5 & $26.6 \%$ \\
\hline 9 & 6 & $\begin{array}{l}2 \mathrm{~N} / \\
3\end{array}$ & 0.05 & 10 & 1 & 374.1 & 1 & 380.0 & $1.6 \%$ & 1 & 380.0 & $1.6 \%$ & 0 & 558.8 & $49.4 \%$ \\
\hline 9 & 9 & $\mathrm{~N}$ & 0.05 & 10 & 1 & 336.4 & 1 & 357.6 & $6.3 \%$ & 1 & 357.6 & $6.3 \%$ & 0 & 491.6 & $46.2 \%$ \\
\hline 9 & 3 & $\mathrm{~N} / 3$ & 0.1 & 0.1 & 3 & 15.3 & 1 & 1282.8 & $8278.7 \%$ & 3 & 15.8 & $2.9 \%$ & 3 & 15.3 & $0.0 \%$ \\
\hline 9 & 6 & $\begin{array}{l}2 \mathrm{~N} / \\
3\end{array}$ & 0.1 & 0.1 & 3 & 15.2 & 1 & 984.0 & $6377.9 \%$ & 3 & 15.2 & $0.0 \%$ & 3 & 15.2 & $0.0 \%$ \\
\hline 9 & 9 & $\mathrm{~N}$ & 0.1 & 0.1 & 3 & 15.2 & 1 & 696.8 & $4487.4 \%$ & 3 & 15.2 & $0.0 \%$ & 3 & 15.2 & $0.0 \%$ \\
\hline 9 & 3 & $\mathrm{~N} / 3$ & 0.1 & 1 & 3 & 103.8 & 1 & 1300.2 & $1152.6 \%$ & 3 & 110.7 & $6.6 \%$ & 2 & 105.2 & $1.4 \%$ \\
\hline 9 & 6 & $\begin{array}{l}2 \mathrm{~N} / \\
3\end{array}$ & 0.1 & 1 & 2 & 91.6 & 1 & 1001.4 & $993.2 \%$ & 2 & 99.9 & $9.0 \%$ & 2 & 91.7 & $0.1 \%$ \\
\hline 9 & 9 & $\mathrm{~N}$ & 0.1 & 1 & 2 & 89.5 & 1 & 714.3 & $698.5 \%$ & 2 & 90.0 & $0.6 \%$ & 2 & 89.5 & $0.0 \%$ \\
\hline 9 & 3 & $\mathrm{~N} / 3$ & 0.1 & 10 & 2 & 689.8 & 1 & 1474.6 & $113.8 \%$ & 2 & 694.8 & $0.7 \%$ & 1 & 816.2 & $18.3 \%$ \\
\hline 9 & 6 & $\begin{array}{l}2 \mathrm{~N} / \\
3\end{array}$ & 0.1 & 10 & 2 & 580.2 & 1 & 1175.8 & $102.6 \%$ & 2 & 622.9 & $7.4 \%$ & 1 & 694.2 & $19.6 \%$ \\
\hline 9 & 9 & $\mathrm{~N}$ & 0.1 & 10 & 1 & 505.7 & 1 & 888.6 & $75.7 \%$ & 2 & 613.0 & $21.2 \%$ & 1 & 576.1 & $13.9 \%$ \\
\hline 27 & 9 & $\mathrm{~N} / 3$ & 0.01 & 0.1 & 2 & 10.0 & 1 & 20.0 & $100.7 \%$ & 2 & 10.0 & $0.0 \%$ & 2 & 10.0 & $0.0 \%$ \\
\hline 27 & 18 & $\begin{array}{l}2 \mathrm{~N} / \\
3\end{array}$ & 0.01 & 0.1 & 2 & 10.0 & 1 & 20.0 & $100.6 \%$ & 2 & 10.0 & $0.0 \%$ & 2 & 10.0 & $0.0 \%$ \\
\hline 27 & 27 & $\mathrm{~N}$ & 0.01 & 0.1 & 2 & 10.0 & 1 & 20.0 & $100.6 \%$ & 2 & 10.0 & $0.0 \%$ & 2 & 10.0 & $0.0 \%$ \\
\hline 27 & 9 & $\mathrm{~N} / 3$ & 0.01 & 1 & 1 & 54.3 & 1 & 54.3 & $0.0 \%$ & 1 & 54.3 & $0.0 \%$ & 1 & 54.3 & $0.0 \%$ \\
\hline 27 & 18 & $\begin{array}{l}2 \mathrm{~N} / \\
3\end{array}$ & 0.01 & 1 & 1 & 54.3 & 1 & 54.3 & $0.0 \%$ & 1 & 54.3 & $0.0 \%$ & 1 & 54.3 & $0.0 \%$ \\
\hline 27 & 27 & $\mathrm{~N}$ & 0.01 & 1 & 1 & 54.3 & 1 & 54.3 & $0.0 \%$ & 1 & 54.3 & $0.0 \%$ & 1 & 54.3 & $0.0 \%$ \\
\hline 27 & 9 & $\mathrm{~N} / 3$ & 0.01 & 10 & 0 & 259.1 & 1 & 397.4 & $53.3 \%$ & 1 & 397.4 & $53.3 \%$ & 0 & 289.2 & $11.6 \%$ \\
\hline 27 & 18 & $\begin{array}{l}2 \mathrm{~N} / \\
3\end{array}$ & 0.01 & 10 & 0 & 142.5 & 1 & 397.3 & $178.9 \%$ & 0 & 157.5 & $10.5 \%$ & 0 & 143.3 & $0.5 \%$ \\
\hline 27 & 27 & $\mathrm{~N}$ & 0.01 & 10 & 0 & 135.0 & 1 & 397.3 & $194.3 \%$ & 0 & 135.1 & $0.0 \%$ & 0 & 135.0 & $0.0 \%$ \\
\hline 27 & 9 & $\mathrm{~N} / 3$ & 0.05 & 0.1 & 5 & 19.4 & 2 & 333.3 & $1622.7 \%$ & 5 & 19.4 & $0.0 \%$ & 5 & 19.4 & $0.0 \%$ \\
\hline 27 & 18 & $\begin{array}{l}2 \mathrm{~N} / \\
3\end{array}$ & 0.05 & 0.1 & 5 & 19.4 & 2 & 114.6 & $492.1 \%$ & 5 & 19.4 & $0.0 \%$ & 5 & 19.4 & $0.0 \%$ \\
\hline 27 & 27 & $\mathrm{~N}$ & 0.05 & 0.1 & 5 & 19.4 & 2 & 107.5 & $455.8 \%$ & 5 & 19.4 & $0.0 \%$ & 5 & 19.4 & $0.0 \%$ \\
\hline 27 & 9 & $\mathrm{~N} / 3$ & 0.05 & 1 & 3 & 113.6 & 2 & 371.9 & $227.3 \%$ & 3 & 114.2 & $0.5 \%$ & 3 & 113.6 & $0.0 \%$ \\
\hline 27 & 18 & $\begin{array}{l}2 \mathrm{~N} / \\
3\end{array}$ & 0.05 & 1 & 3 & 113.3 & 2 & 153.1 & $35.2 \%$ & 3 & 113.3 & $0.0 \%$ & 3 & 113.3 & $0.0 \%$ \\
\hline 27 & 27 & $\mathrm{~N}$ & 0.05 & 1 & 3 & 113.3 & 2 & 146.1 & $29.0 \%$ & 3 & 113.3 & $0.0 \%$ & 3 & 113.3 & $0.0 \%$ \\
\hline 27 & 9 & $\mathrm{~N} / 3$ & 0.05 & 10 & 2 & 664.7 & 2 & 757.3 & $13.9 \%$ & 2 & 757.3 & $13.9 \%$ & 1 & 898.2 & $35.1 \%$ \\
\hline 27 & 18 & $\begin{array}{l}2 \mathrm{~N} / \\
3\end{array}$ & 0.05 & 10 & 2 & 513.2 & 1 & 1630.9 & $217.8 \%$ & 2 & 538.5 & $4.9 \%$ & 1 & 685.0 & $33.5 \%$ \\
\hline 27 & 27 & $\mathrm{~N}$ & 0.05 & 10 & 1 & 463.9 & 1 & 851.2 & $83.5 \%$ & 2 & 531.5 & $14.6 \%$ & 1 & 514.2 & $10.8 \%$ \\
\hline 27 & 9 & $\mathrm{~N} / 3$ & 0.1 & 0.1 & 7 & 24.0 & 3 & 1718.7 & $7061.3 \%$ & 7 & 24.0 & $0.0 \%$ & 7 & 24.0 & $0.0 \%$ \\
\hline 27 & 18 & $\begin{array}{l}2 \mathrm{~N} / \\
3\end{array}$ & 0.1 & 0.1 & 7 & 24.0 & 3 & 873.5 & $3539.7 \%$ & 7 & 24.0 & $0.0 \%$ & 7 & 24.0 & $0.0 \%$ \\
\hline 27 & 27 & $\mathrm{~N}$ & 0.1 & 0.1 & 7 & 24.0 & 3 & 372.7 & $1452.8 \%$ & 7 & 24.0 & $0.0 \%$ & 7 & 24.0 & $0.0 \%$ \\
\hline 27 & 9 & $\mathrm{~N} / 3$ & 0.1 & 1 & 5 & 152.9 & 3 & 1753.6 & $1046.7 \%$ & 5 & 155.1 & $1.4 \%$ & 5 & 153.0 & $0.1 \%$ \\
\hline 27 & 18 & $\begin{array}{l}2 \mathrm{~N} / \\
3\end{array}$ & 0.1 & 1 & 5 & 151.7 & 3 & 908.4 & $498.9 \%$ & 5 & 151.7 & $0.0 \%$ & 5 & 151.7 & $0.0 \%$ \\
\hline 27 & 27 & $\mathrm{~N}$ & 0.1 & 1 & 5 & 151.7 & 3 & 407.6 & $168.7 \%$ & 5 & 151.7 & $0.0 \%$ & 5 & 151.7 & $0.0 \%$ \\
\hline 27 & 9 & $\mathrm{~N} / 3$ & 0.1 & 10 & 4 & 983.0 & 3 & 2102.5 & $113.9 \%$ & 4 & 1039.6 & $5.8 \%$ & 3 & 1168.2 & $18.8 \%$ \\
\hline 27 & 18 & $\begin{array}{l}2 \mathrm{~N} / \\
3\end{array}$ & 0.1 & 10 & 4 & 771.9 & 3 & 1257.3 & $62.9 \%$ & 4 & 850.6 & $10.2 \%$ & 3 & 855.3 & $10.8 \%$ \\
\hline 27 & 27 & $\mathrm{~N}$ & 0.1 & 10 & 3 & 662.9 & 3 & 756.5 & $14.1 \%$ & 3 & 756.5 & $14.1 \%$ & 3 & 674.7 & $1.8 \%$ \\
\hline \multicolumn{5}{|c|}{ Average gap } & - & & \multicolumn{3}{|c|}{$610.5 \%$} & \multicolumn{3}{|c|}{$6.8 \%$} & $4.5 \%$ & & \\
\hline
\end{tabular}

\section{References}

Al Hanbali, A., van der Heijden, M., 2013. Interval availability analysis of a two-echelon, multi-item system. Eur. J. Oper. Res. 228 (3), 494-503.

Banerjee, A., Paul, A., 2005. Average fill rate and horizon length. Oper. Res. Lett. 33 (5), 525-530.

Basten, R.J.I., van Houtum, G.-J., 2014. System-oriented inventory models for spare parts. Surveys in Operations Research and Management Science 19 (1), 34-55.

Berg, M., Posner, M., 1985. Customer delays in $\mathrm{m} / \mathrm{m} / \mathrm{c}$ repair systems with spares. Nav. Res. Logist. 32 (2), 287-299.

Caggiano, K.E., Jackson, P.L., Muckstadt, J.A., Rappold, J.A., 2007. Optimizing service parts inventory in a multiechelon, multi-item supply chain with time-based customer service-level agreements. Oper. Res. 55 (2), 303-318.

Chen, J., Lin, D.K., Thomas, D.J., 2003. On the single item fill rate for a finite horizon. Oper. Res. Lett. 31 (2), 119-123.

CSIMarket, 2019. Capital Goods Sector. http://csimarket.com/Industry/Industry_Data. php?s $=200$.
Dreyfuss, M., Giat, Y., 2017. Optimal spares allocation to an exchangeable-item repair system with tolerable wait. Eur. J. Oper. Res. 261 (2), 584-594.

Ge, Q., Peng, H., van Houtum, G.-J., Adan, I., 2018. Reliability optimization for series systems under uncertain component failure rates in the design phase. Int. J. Prod. Econ. 196, 163-175.

Hajek, B., 1985. Extremal splittings of point processes. Math. Oper. Res. 10 (4), 543-556. Hopp, W., Spearman, M., 2011. Factory Physics, third ed. Waveland Press.

Hu, Q., Boylan, J.E., Chen, H., Labib, A., 2018. OR in spare parts management: a review. Eur. J. Oper. Res. 266 (2), 395-414.

Huiskonen, J., 2001. Maintenance spare parts logistics: special characteristics and strategic choices. Int. J. Prod. Econ. 71 (1-3), 125-133.

Kim, S.-H., Cohen, M.A., Netessine, S., Veeraraghavan, S., 2010. Contracting for infrequent restoration and recovery of mission-critical systems. Manag. Sci. 56 (9), 1551-1567.

Knofius, N., van der Heijden, M.C., Zijm, W.H., 2019. Consolidating spare parts for asset maintenance with additive manufacturing. Int. J. Prod. Econ. 208, 269-280.

Koole, G., 2007. Monotonicity in markov reward and decision chains: theory and applications. Foundations and Trends ${ }^{\circledast}$ in Stochastic Systems 1 (1), 1-76. 
Larsen, C., Thorstenson, A., 2014. The order and volume fill rates in inventory control systems. Int. J. Prod. Econ. 147, 13-19.

Luo, M., Wu, S., 2018. A mean-variance optimisation approach to collectively pricing warranty policies. Int. J. Prod. Econ. 196, 101-112.

Luo, W., Shang, K.H., 2019. Managing inventory for firms with trade credit and deficit penalty. Oper. Res. 67 (2), 468-478.

Murota, K., 2003. Discrete Convex Analysis. SIAM.

Murota, K., 2005. Note on multimodularity and l-convexity. Math. Oper. Res. 30 (3), 658-661.

Öner, K., Franssen, R., Kiesmüller, G., Van Houtum, G., 2007. Life cycle costs measurement of complex systems manufactured by an engineer-to-order company. In: The 17th International Conference on Flexible Automation and Intelligent Manufacturing, pp. 569-589.

Sherbrooke, C.C., 1968. Metric: a multi-echelon technique for recoverable item control. Oper. Res. 16 (1), 122-141.

Sleptchenko, A., Turan, H.H., Pokharel, S., ElMekkawy, T.Y., 2019. Cross-training policies for repair shops with spare part inventories. Int. J. Prod. Econ. 209, 334-345.
Song, J.-S., 1998. On the order fill rate in a multi-item, base-stock inventory system. Oper. Res. 46 (6), 831-845.

Song, J.-S., Xiao, L., Zhang, H., Zipkin, P., 2017. Optimal policies for a dual-sourcing inventory problem with endogenous stochastic lead times. Oper. Res. 65 (2), 379-395.

Thomas, D.J., 2005. Measuring item fill-rate performance in a finite horizon. Manuf. Serv. Oper. Manag. 7 (1), 74-80.

Topan, E., Tan, T., van Houtum, G.-J., Dekker, R., 2018. Using imperfect advance demand information in lost-sales inventory systems with the option of returning inventory. IISE Transactions 50 (3), 246-264.

van Wijk, A., Adan, I., van Houtum, G.-J., 2019. Optimal lateral transshipment policies for a two location inventory problem with multiple demand classes. Eur. J. Oper. Res. 272 (2), 481-495.

Wise, R., Baumgartner, P., 1999. Go downstream: the new profit imperative in manufacturing. Harv. Bus. Rev. 77 (5), 133-141 01.

Zipkin, P., 2008. On the structure of lost-sales inventory models. Oper. Res. 56 (4), 937-944. 